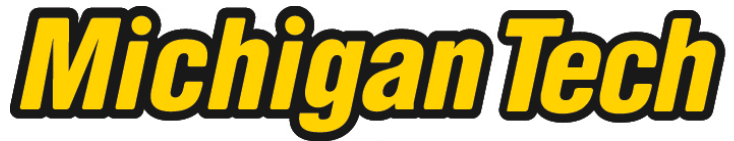 \\ Michigan Technological University Create the Future Digital Commons @ Michigan Tech
}

Performance evaluation of a novel asymmetric capacitor using a light-weight, carbon foam supported nickel electrode

Padmanaban Sasthan Kuttipillai

Michigan Technological University

Follow this and additional works at: https://digitalcommons.mtu.edu/etds

Part of the Chemistry Commons

Copyright 2011 Padmanaban Sasthan Kuttipillai

\section{Recommended Citation}

Kuttipillai, Padmanaban Sasthan, "Performance evaluation of a novel asymmetric capacitor using a lightweight, carbon foam supported nickel electrode", Master's Thesis, Michigan Technological University, 2011.

https://doi.org/10.37099/mtu.dc.etds/34

Follow this and additional works at: https://digitalcommons.mtu.edu/etds

Part of the Chemistry Commons 


\title{
PERFORMANCE EVALUATION OF A NOVEL ASYMMETRIC CAPACITOR USING A LIGHT-WEIGHT, CARBON FOAM SUPPORTED NICKEL ELECTRODE
}

\author{
by \\ Padmanaban Sasthan Kuttipillai
}

\begin{abstract}
A THESIS
Submitted in partial fulfillment of the requirements for the degree of MASTER OF SCIENCE

(Chemistry)
\end{abstract}

\section{MICHIGAN TECHNOLOGICAL UNIVERSITY}

2011

(C) 2011 Padmanaban Sasthan Kuttipillai 
This thesis, "Performance Evaluation of a Novel Asymmetric Capacitor using a Light-weight, Carbon Foam Supported Nickel Electrode," is hereby approved in partial fulfillment of the requirements for the Degree of MASTER OF SCIENCE IN CHEMISTRY.

Department of Chemistry

Signatures:

Thesis Advisor

Dr. Bahne C. Cornilsen

Thesis Co-Advisor

Dr. Tony N. Rogers

Department Chair

Dr. Sarah A. Green

Date 


\section{Table of Contents}

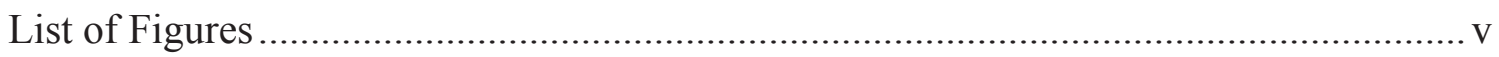

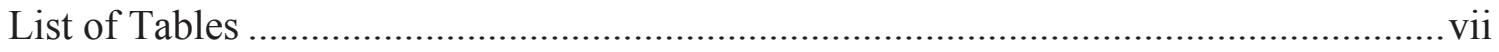

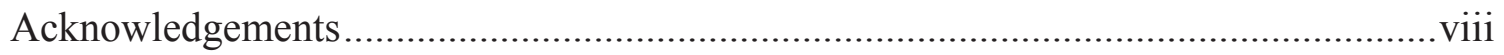

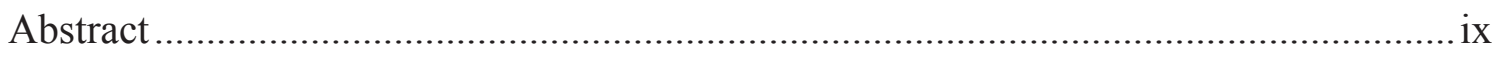

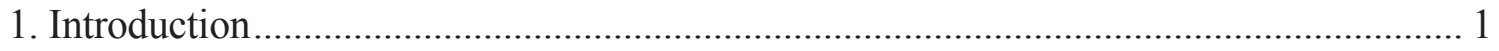

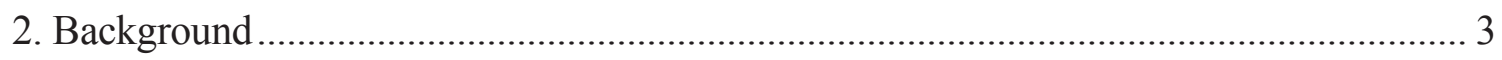

2.1 Significance of Electrochemical Energy Storage ..................................................... 3

2.2 A Brief History of Electrochemical Capacitors........................................................... 4

2.3 Scientific Principles of the Electrochemical Capacitor .............................................. 6

2.4 Origin of Electrochemical Capacitance ................................................................. 8

2.5 Classification of Electrochemical Capacitors......................................................... 14

2.6 Literature Review on Electrochemical Capacitors ................................................ 15

3. Methods and Characterization Techniques..................................................................... 22

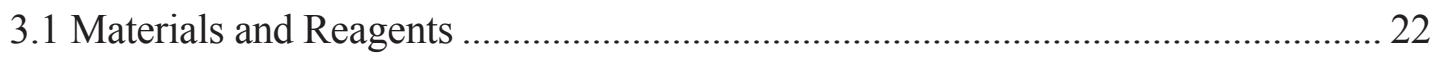

3.2 Positive Electrode Synthesis ............................................................................... 22

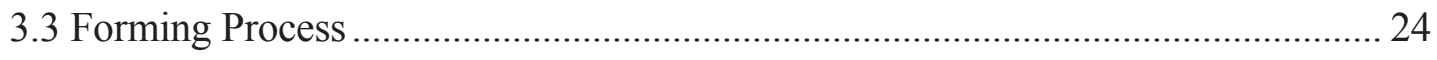

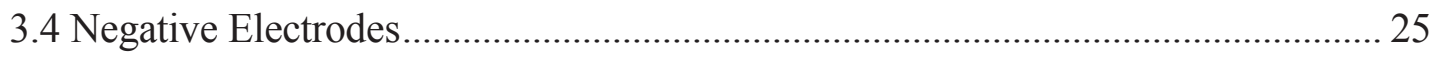

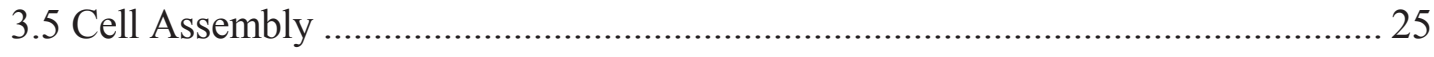

3.6 Electrochemical Characterization .................................................................... 27 


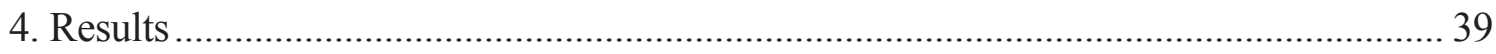

4.1 Electrochemical Characterization of Symmetric Capacitor ................................... 39

4.2 Electrochemical Characterization of Asymmetric Capacitor.................................. 45

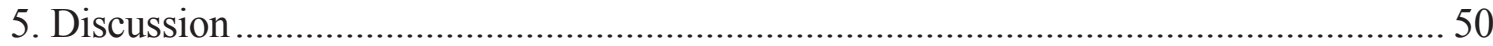

5.1 Evaluation of Symmetric Capacitor................................................................ 50

5.2 Evaluation of Asymmetric Capacitor …............................................................... 52

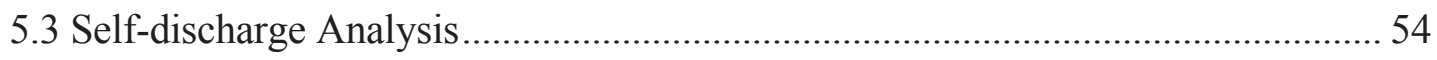

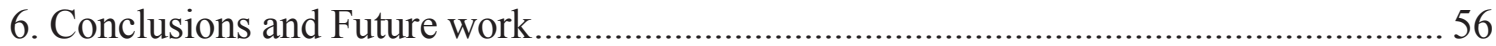

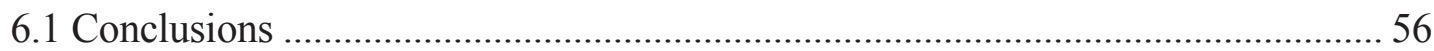

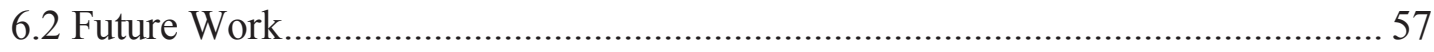

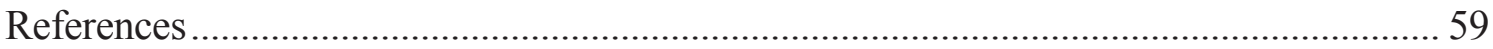

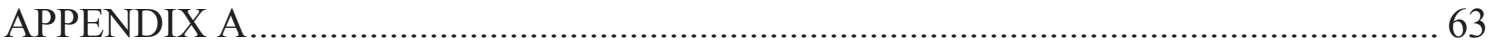

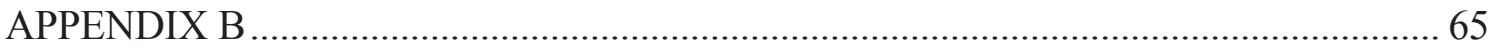

APPENDIX C 


\section{List of Figures}

Figure 2.1. Projection of fuel consumption and the affects of hybrid vehicles in the future

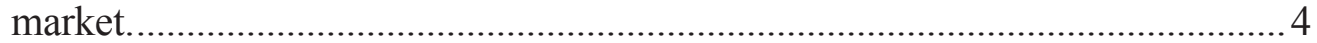

Figure 2.2. Ragone plot of various electrochemical devices............................................... 5

Figure 2.3. Schematic diagram representing the conventional parallel plate capacitor. ........6

Figure 2.4. Visual representation of a metal/solution interface in a solution ........................

Figure 2.5. Early Helmholtz model showing the inner Helmholtz layer...............................10

Figure 2.6. Gouy-Chapman model with the OHL to the right of the IHL............................ 11

Figure 2.7. Flow-chart describing different type of Capacitors....................... 14

Figure 3.1. The components of a Swagelok-type PFA cell ...............................................26

Figure 3.2. Assembled Swagelok-type PFA cell .................................................................2

Figure 3.3. Cyclic voltammetric behavior of ideal capacitor................................................2

Figure 3.4. Current and voltage response of AC signal for a resistor....................................32

Figure 3.5. Current and voltage response of a capacitor for an AC signal ............................33

Figure 3.6. Current and voltage relation in the resistor and capacitor series circuit..............35

Figure 3.7. Ladder equivalent circuit for porous electrodes. .................................................36

Figure 3.8. Conway's model circuit for an electrode with pseudo- capacitance, $\mathrm{C}_{\Phi} \ldots \ldots . . . . .37$

Figure 4.1. CV plot obtained at different scan rates in the symmetric capacitor ..................39

Figure 4.2. Potential vs. time response of the symmetric capacitor at different current densities

Figure 4.3. Ragone plot for the symmetric capacitor 42

Figure 4.4. Impedance data for the symmetric capacitor compared to data fitted with the ladder equivalent circuit model 
Figure 4.5. Frequency vs. complex power plot for the symmetric capacitor 44

Figure 4.6. Potential vs. time response for the asymmetric (SW-77) capacitor obtained at different current densities. ........................................................................ 45

Figure 4.7. Potential vs. time response for the asymmetric capacitor at different cycle

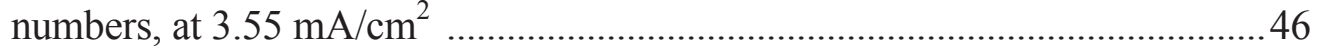

Figure 4.8. Ragone plot for the asymmetric capacitor................................................... 47

Figure 4.9. Capacity variation with cycle number for the asymmetric capacitor ...............48

Figure 4.10. Nyquist plots obtained at $250^{\text {th }}$ and $14,250^{\text {th }}$ cycles for the asymmetric

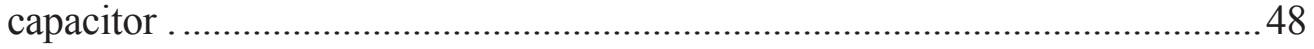

Figure 4.11. Frequency vs. complex power plot for the asymmetric capacitor..................49

Figure 4.12. Open circuit potential vs. time response of the asymmetric capacitor ...........49 


\section{List of Tables}

Table 2.1. Comparison of double-layer and pseudo-capacitance properties ..................... 13

Table 2.2. The properties of various carbon materials including capacitance ................... 16

Table 2.3. This table summarizes the performance parameters for the five capacitor systems studied by Zheng, et al ${ }^{37}$................................................................ 20

Table 3.1. The components of a Swagelok-type PFA cell ...............................................26

Table 4.1. Cell specific capacitance and columbic efficiency calculated for the symmetric capacitor, at six different CV scan rates ....................................................... 40

Table 4.2. Cell specific capacitance, energy, and power density calculated at four different current densities ............................................................................. 41

Table 4.3. Equivalent circuit parameters for the symmetric capacitor compared with those for a commercial carbon sheet material ................................................. 43

Table 4.4. Cell capacitance, power and energy densities calculated for the asymmetric capacitor at different current densities ........................................................... 46 


\section{Acknowledgements}

In the first place, I would like to express my deepest and sincere gratitude to my mentor Dr. Bahne Cornilsen for providing me with his diligent support and guidance. His enduring motivation has fostered in me, a never-ending opportunity to excel during the course of this research and will be a pillar of support throughout my professional career. I am grateful to my co-advisor Dr. Tony Rogers, and to committee member Dr. Shiyue Fang for providing their time and invaluable review of this manuscript. My sincere thanks to Dr. Ralph Brodd for his input and insightful discussions during this research. Thanks to Celgard, LLC for generously donating the separator for this study. This work wouldn't have been possible without the financial support from the DOE and MUCI agencies.

I thank my colleagues: Matthew B. Chye for his help in making positive electrodes and Jinjin Wang for her great effort in synthesizing carbon electrodes. I am thankful to Mark Laiti at Laiti Jewelers for his help repairing gold electrodes. I would like to pay tribute to all my friends in Houghton, who have been more than a friendly ear or an encouraging word. Finally, I would like to thank my parents, Sasthan Kuttipillai and Padmavathy, my loving wife, Ambujam, and my brother Arun for being extra supportive and determined towards my education. I am deeply indebted to the Wenberg family, who has let me into their lives and provided a home away from home environment in this

distant land during my graduate studies. They have been the source of encouragement and unconditional love, and I dedicate my work to their indomitable spirit. 


\begin{abstract}
Electrochemical capacitors have been an important development in recent years in the field of energy storage. Capacitors can be developed by utilizing either double layer capacitance at the electrode/solution interfaces alone or in combination with a battery electrode associated with a faradic redox process in one electrode. An asymmetric capacitor consisting of electrochemically deposited nickel hydroxide, supported on carbon foam as a positive electrode and carbon sheet as a negative electrode has been successfully assembled and cycled. One objective of this study has been to demonstrate the viability of the nickel carbon foam positive electrode, especially in terms of cycle life. Electrochemical characterization shows stable, high cycle performance in 26 wt. \% $\mathrm{KOH}$ electrolyte with a maximum energy density of $4.1 \mathrm{Wh} / \mathrm{Kg}$ and a relaxation time constant of $6.24 \mathrm{~s}$. This cell has demonstrated high cycle life, 14,500 cycles, with efficiency better than $98 \%$. In addition, the cell failure mechanism and self-discharge behavior of the aforesaid capacitor are analyzed.
\end{abstract}




\section{INTRODUCTION}

Nickel-based batteries have widespread application ranging from power tools to satellites. (Nickel oxyhydroxide is the actual active material.) The current collector is one

of the most important parts of any battery system since it influences the conductivity and energy density of a battery system. The Departments of Chemistry and of Chemical Engineering at Michigan Technological University have recently focused on replacing the existing nickel plaque current collector with a light, cheap, and readily available material, carbon foam. This carbon foam can cut the weight of the current collector in a nickel electrode by up to $25 \%$, hence increasing the energy density of the system.

The objective of this thesis is to capitalize on the advantage of light weight carbon foam materials for use in an asymmetric, Electrochemical Capacitor (EC) application for the first time. A key advantage of the asymmetric configuration is that the overall capacitance of any series connected capacitor device is found by equation 1.1 . Here, $\mathrm{C}_{\mathrm{T}}$ is the total capacitance of the cell. $\mathrm{C}_{1}, \mathrm{C}_{2}$ are the capacitances of the individual electrodes in the cell. For the asymmetric capacitor, $\mathrm{C}_{1}$ is not equal to $\mathrm{C}_{2}$.

$$
\frac{1}{\mathrm{C}_{\mathrm{T}}}=\frac{1}{\mathrm{C}_{1}}+\frac{1}{\mathrm{C}_{2}}
$$

The practical limitation of symmetric capacitor technology (where $\mathrm{C}_{1} \approx \mathrm{C}_{2}$ ) is that the total capacitance is reduced to half of the individual electrode capacitances owing to this fundamental reciprocal law of series capacitance. In order to overcome this practical short-coming, the relatively new concept of asymmetric capacitors has been introduced. An 
asymmetric capacitor incorporates a faradic (or battery) electrode as one of the electrodes. ${ }^{1}$ The battery electrode has a capacitance associated with the faradaic redox reaction of $\sim 10$ times that of the capacitance of an electrochemical double layer. If the battery cathode is substituted for one of the electrodes in a capacitor, for example $\mathrm{NiOOH}$, then substituting $C_{2}=10 C_{1}$ in equation 1.1, the capacitance of the electrochemical capacitor is essentially doubled. $1 / \mathrm{C}_{\mathrm{T}}=1 / \mathrm{C}_{1}+1 / 10 \mathrm{C}_{1}$ and $\mathrm{C}_{\mathrm{T}} \approx \mathrm{C}_{1}$. Asymmetric capacitors are also referred to as a "hybrid" system. In addition to this, the faradaic electrode offers good charge retention and higher energy density to this capacitor configuration.

The goal of this work, therefore, is to demonstrate the design and electrochemical performance characterization of an asymmetric capacitor in which electrodeposited nickel oxyhydroxide/carbon foam positive electrode and an in-house, carbon black, double-layer negative electrode are employed. For the latter, a carbon sheet electrode made of carbon black (Ketjenblack) and PTFE was synthesized. The suitability of this material in this electrochemical capacitor application is tested by assembling a symmetric capacitor, and its electrochemical performance is characterized.

These electrodes have been fully characterized, including self-discharge, power performance (maximum power density and relaxation time) and cycle life.

Various authors have reported using nickel hydroxide synthesized via chemical routes as a positive electrode in an asymmetric capacitor ${ }^{2,3}$ However in this thesis research, the electrode was synthesized using electrochemical, cathodic deposition. ${ }^{4,5}$ The electrochemical deposition offers a viable solution to selectively synthesize $\alpha$-nickel hydroxide electrode. 


\section{BACKGROUND}

\subsection{Significance of Electrochemical Energy Storage}

Electrochemical energy storage technologies such as batteries, fuel cells and electrochemical capacitors are under serious consideration to satisfy the increasing demand for energy and growing concerns about energy conservation and global warming. Several research programs have been launched through various government, university, and commercial ventures to develop the chemistries and technologies that will improve the generation and distribution of energy. In order to develop and commercialize electrochemical energy storage devices in the US, the United States Advanced Battery Consortium (USABC) was formed by the collaboration of the U.S. Department of Energy and leading U.S. automotive companies. ${ }^{6}$ The USABC actively engages in finding high energy battery and ultra-capacitor technologies for various applications such as Plug-in Hybrid Electric Vehicles (PHEVs) and Electric Vehicles (EVs). It also provides guidelines to validate these technologies by conducting benchmarking activities. The ultimate aim of all these research efforts is to shift the transportation industry's strong dependence on oil to the domestically powered U.S. electric grid. The Department of Energy has projected that transportation will account for an $87 \%$ increase in petroleum consumption in the year 2030 due to the growth in the light-duty vehicle industry. The number of vehicles on the road is expected to be 500 million at the end of 2030. If half of those vehicles were PHEVs, then the fuel consumption would drop six million barrels per day; and, if all of the vehicles were PHEVs, the U.S. oil consumption would drop 10 million barrels per day (see Fig.2.1). ${ }^{6}$ 


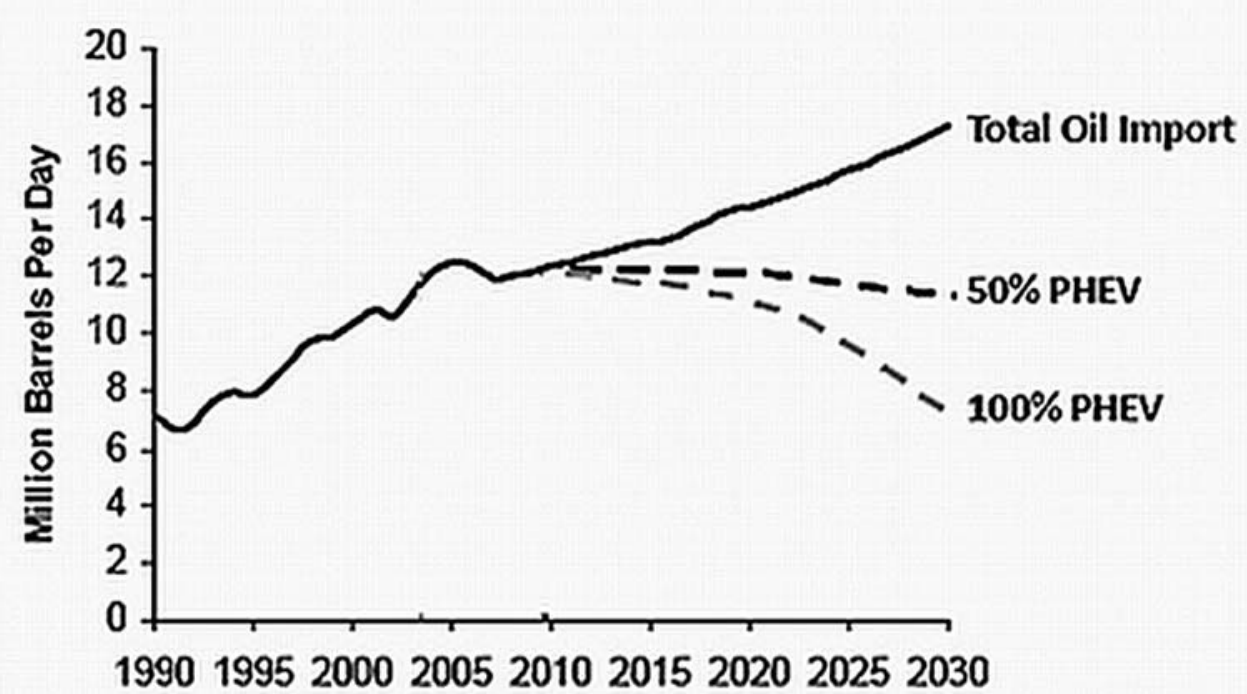

Figure 2.1. Projection of fuel consumption and the affects of hybrid vehicles in the future market. ${ }^{6}$

\subsection{A Brief History of Electrochemical Capacitors}

Electrochemical capacitors have been known for many years. The energy storage capability and the power draining capacity of these devices lie in between rechargeable batteries and traditional capacitors (see Fig. 2.2).

The first patent for an electrochemical capacitor was granted to Becker from the General Electric Co. in 1957, where he employed high surface area carbon electrodes. ${ }^{7}$ The marketing of these devices was undertaken in late 1969 by SOHIO. ${ }^{8}$ The energy is stored electrostatically in this device as an interfacial double-layer capacitance at the particle/solution interface of the carbon electrodes. In 1971, other types of capacitors were described by Tarasatti and Buzzanco. ${ }^{9}$ These authors noted, for the first time, that the 
electrochemical charging behavior of metal oxide films was similar to that of a capacitor during the cyclic voltammetry experiments conducted in ruthenium oxide films. Between

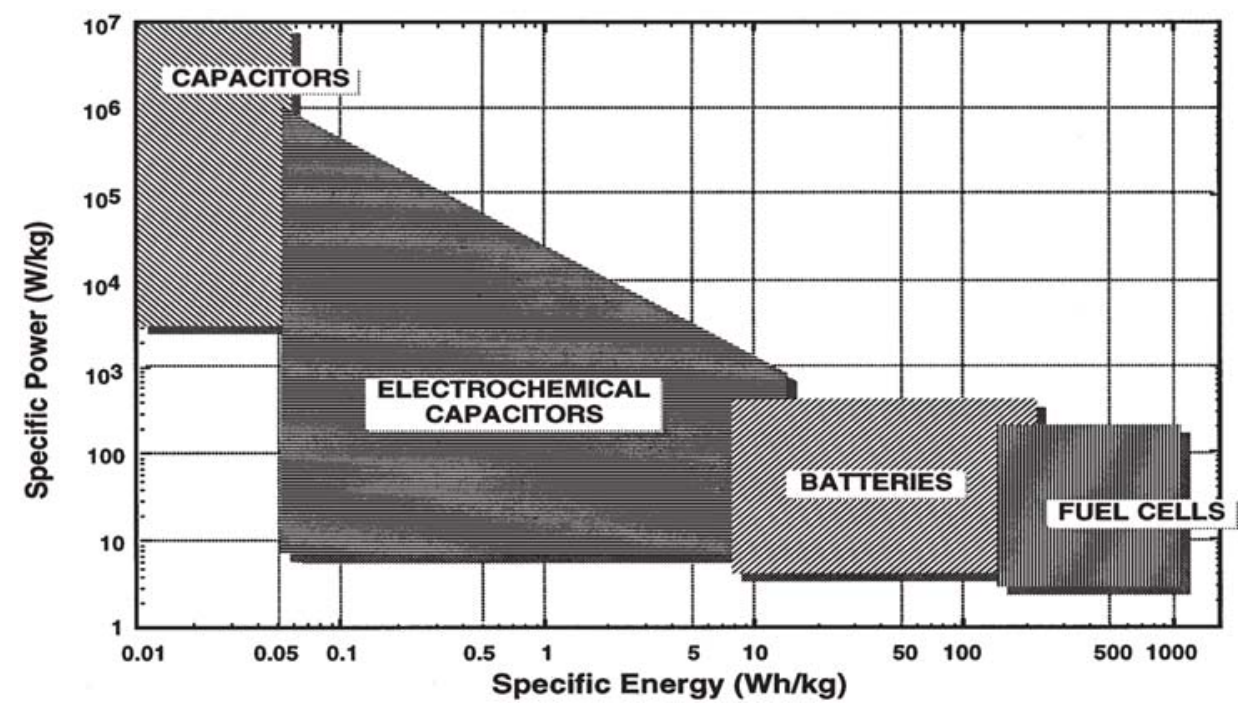

Figure 2.2. Ragone plot of the specific power and specific energy capabilities of various electrochemical devices, including electrochemical capacitors. ${ }^{10}$

1975 and 1980, Conway and his co-workers did extensive fundamental research on the metal oxide type of electrochemical capacitor which offered a very high specific capacitance. ${ }^{11}$ Those authors reported this type of metal oxide capacitor involves surface pseudo-capacitance due to a faradaic transfer of charge between the electrode surface and the electrolyte. This transfer allows more charge, and therefore more energy, to be stored than in the double-layer alone and greatly increases device capacitance. Due to high cost of the active materials these capacitors find little commercial application. In the nineties electrochemical capacitors (ECs) were an important development in the context of electric vehicles. The US Department of Energy initiated an ultra-capacitor development program in 1989. The primary objective of this program was to develop an electrochemical 
capacitor which could boost the performance of batteries or fuel cells in hybrid electric vehicles by providing the necessary power for acceleration. Today several companies such as Maxwell Technologies, SAFT, FastCAP Systems, Siemens Matsushita NEC, Panasonic, ELNA, TOKIN, and several others have invested in electrochemical capacitor development as a promising technology for electric vehicle power systems for SLI (starting, lighting, and ignition) as well as applications in consumer electronics such as digital cameras, flashlights and media players.

\subsection{Scientific Principles of the Electrochemical Capacitor}

The electrochemical capacitor works fundamentally the same way as the traditional electrostatic capacitor. Figure 2.3 shows a conventional capacitor, consisting of two parallel plates, with area A, and separated by a distance, $\mathrm{d}$, by a dielectric material.

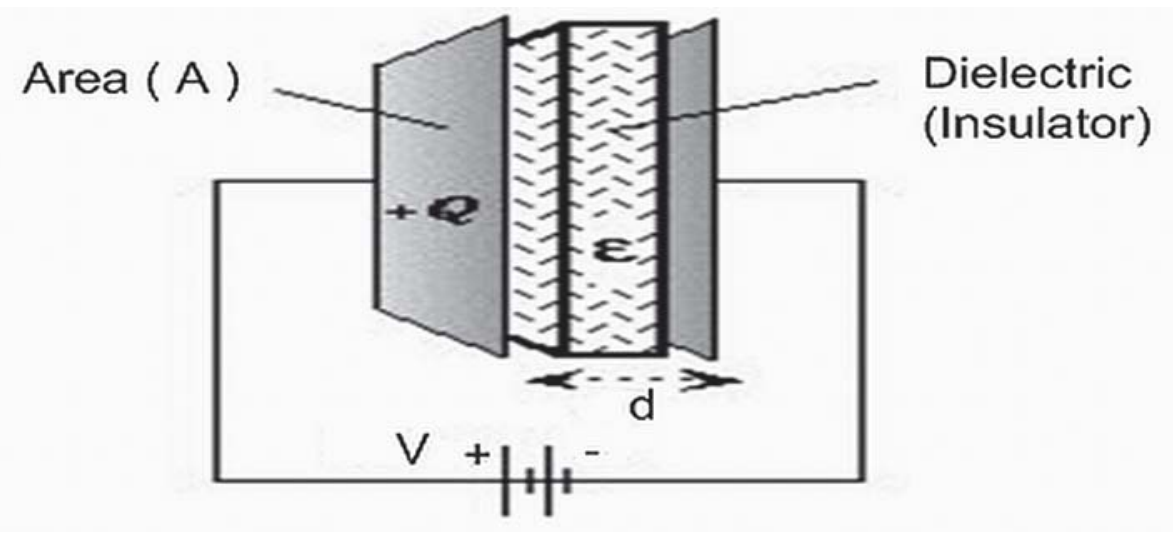

Figure 2.3. Schematic diagram representing the conventional parallel plate capacitor.

When the external potential, $\mathrm{V}$, is applied to the capacitor, the current flows and charge accumulates on the plates until the capacitor potential reaches the external potential. 
Capacitance, $\mathrm{C}$, is defined as the amount of electric charge, $\mathrm{q}$, stored at a given potential, $\mathrm{V}$ (see eqn. 2.1). The capacitance is measured in units of Farads (F) which are equal to one coulomb per volt $(1 \mathrm{~F}=1 \mathrm{C} / \mathrm{V})$. The energy stored in a parallel plate capacitor is equal to the work done to move charge from one plate to another. Consider a capacitance, C, holding a charge $+q$ on one plate and $-\mathrm{q}$ on the other. Moving a small element of charge $\mathrm{dq}$ from one plate to the other against the potential difference $E=q / C$ requires the work, $d W$ (see eqn.2.2). The work $\mathrm{W}$ is measured in joules. $\mathrm{q}$ is the charge measured in coulombs, and $\mathrm{C}$ is the capacitance. The total energy stored in a capacitor can be found by integrating equation 2.2, to give equation 2.3.

$$
\begin{gathered}
\mathrm{C}=\mathrm{q} / \mathrm{E} \\
\mathrm{dW}=\mathrm{q} / \mathrm{C} \mathrm{dq} \\
\mathrm{W}_{\text {charging }}=\int_{O}^{Q} \frac{q}{C} d q=\frac{1}{2} \frac{Q^{2}}{C}=\frac{1}{2} C E^{2}
\end{gathered}
$$

The capacitance of the parallel plate capacitor can also be calculated if the geometry of the plates and the dielectric properties of the medium between the plates are known based on equation 2.4 , where $A$ is the area of overlap of the two plates, $\varepsilon_{\mathrm{r}}$ is the relative dielectric constant of the medium between the plates (for a vacuum, $\varepsilon_{\mathrm{r}}=1$ ), $\varepsilon_{0}$ is the permittivity of free space $\left(\varepsilon_{0} \approx 8.854 \times 10^{-12} \mathrm{~F} \mathrm{~m}^{-1}\right)$ and $\mathrm{d}$ is the separation between the plates. ${ }^{1}$

$$
\mathrm{C}=\varepsilon_{\mathrm{r}} \varepsilon_{0} \mathrm{~A} / \mathrm{d}
$$

From equation.2.4, it is obvious that the capacitance is related to the overlapping area of the plates and inversely proportional to the separation between the plates. 
Therefore an electrochemical capacitor, consisting of a high surface area carbon of 2000 $\mathrm{m}^{2} / \mathrm{g}$ with a double layer thickness of 5 to $10 \AA$ (associated with the interface between electrode and electrolyte), offers a huge specific capacitance of $10-18 \mathrm{~F} / \mathrm{g}$ (when $\varepsilon_{\mathrm{r}}$ is 1$){ }^{12}$

\subsection{Origin of Electrochemical Capacitance}

\subsubsection{Double-Layer}

A double layer appears on any surface of an electrode whenever it is placed in a solution. Consider the metal/solution interface shown in the Fig. 2-4. When the metal is under potentiostatic control (under $\mathrm{q}_{\mathrm{w}}$ ) there will be either an excess ( $\mathrm{q}_{\mathrm{m}}$ is negative) or a deficit of free electrons ( $q_{M}$ is positive) at the surface of the metal. A number of processes can occur in the electrode/electrolyte interface including contact adsorption and double layer formation. Solvated anions such as chloride, hydroxide, or cyanide can directly adsorb on metal electrodes due to chemical interaction between the host and these ions. During this process these ions lose part of their solvation sheath in the aqueous media which facilitates a metal-ion bond on the surface of the electrode. This process is referred to as "contact" adsorption. The region which contains these contact adsorbed ions is known as the Inner Helmholtz Layer (IHL). In addition to this, the excess charges on the metal can attract other particles in the solution such as dipole to preferentially orient in the vicinity of the metal solution interface and form a layer. This formed layer of solvated ions is the so called Outer Helmholtz Layer (OHL). The charge densities on the electrode and in the OHL are assumed to be equal and opposite in sign. Figure 2.4 depicts these two layers and the variation of potential from the electrode surface. Therefore, the interface can be approximated by a double-layer, one layer being the OHL and the second one on the electrode surface (the IHL). 


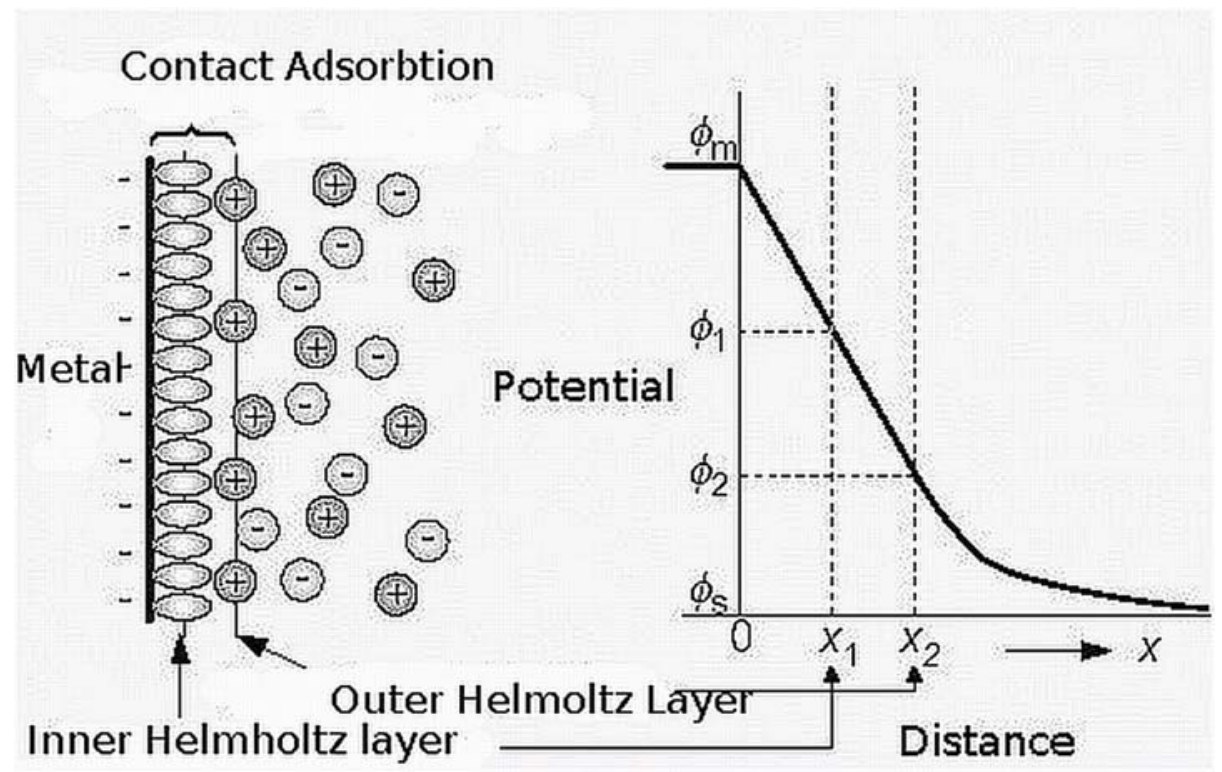

Figure 2.4. Visual representation of a metal/solution interface in a solution and the potential profile of the electrified interface measured from the metal electrode surface.

\subsubsection{Electrochemical Double layer Models}

\section{a) Helmholtz Model}

The term double-layer was first coined by Helmholtz during the $18^{\text {th }}$ century. Various models have been proposed to represent the electrified interface in electrochemical cells. The simplest model was proposed by Helmholtz-Perin. They explained that the excess charge on the metal would draw the oppositely charged, randomly dispersed ions in the solution and form a rigid counter layer. ${ }^{13}$ Thus the electrified interface will consist of two oppositely charged sheets of charges, one on the current collector and another at the solution interface. This model can be visualized as a parallel plate capacitor consisting of two plates of opposite charges. Figure 2.5 shows the contact adsorbed ions and the inner Helmholtz layer formed adjacent to the electrode surface. The Helmholtz-Perin model 
predicts that the capacitance is constant and does not change with the potential; hence, the theory failed to explain the marked dependence of capacitance on potential.

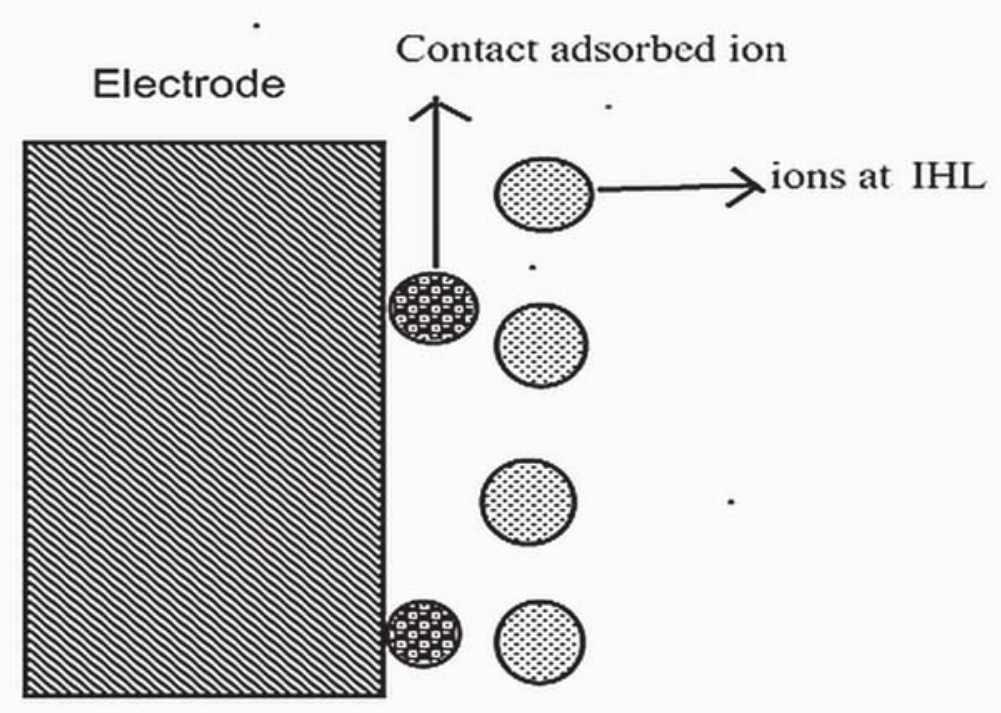

Figure 2.5. Early Helmholtz model showing the inner Helmholtz layer.

\section{b) Gouy-Chapman Model}

Gouy-Chapman proposed an alternative model in which they removed the restriction of forming an rigid ionic layer (OHL) as explained in the early Helmholtz model. This theory assumed that the ions were point charges and the counter ions at the inner Helmholtz layer are not rigidly held. They considered the thermal disarray in solution and suggested that the ions tend to diffuse into the bulk liquid phase. Thus the electrified interface no longer has equal and oppositely charged layers on both sides. They also proposed the excess charge density in the solution decreases with the distance from the electrode due to the diffusion process of solvated ions. Hence the term "diffuse doublelayer" was introduced to the scientific community. The Gouy-Chapman theory describes 
the double-layer consisting of an electrode with a cloud of oppositely charged ions in the solution, the concentration of the oppositely charged ions decreasing with distance from the surface (Figure 2.6). ${ }^{14}$

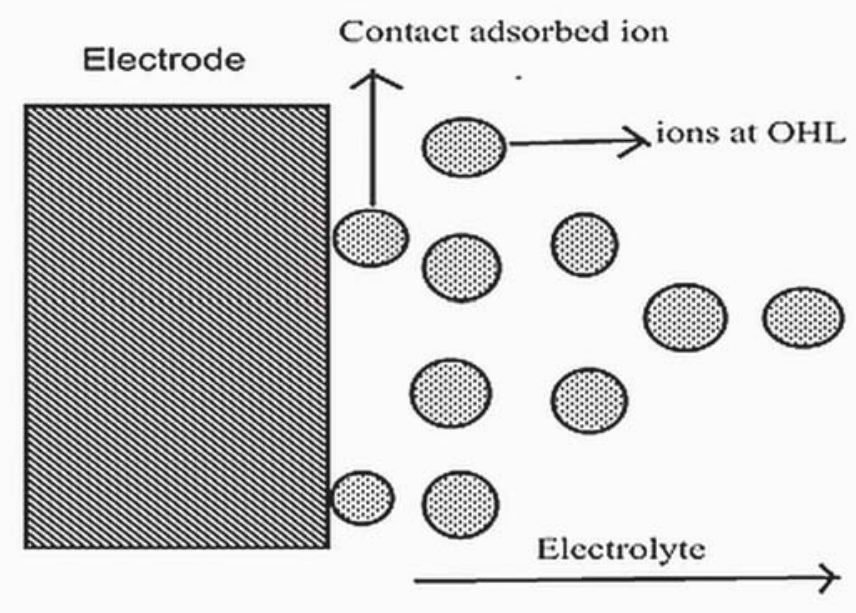

Figure 2.6. Gouy-Chapman model with the OHL to the right of the IHL.

This theory is still not entirely accurate. Experimental double-layer thickness is generally found to be greater than the calculated value based on this model. This is because of the fact that the model neglected the ionic interaction which would definitely become important at high solution concentration and the model also assumed that the dielectric constant is constant between the metal and electrolyte solution.

\section{c) Stern Model}

The Stern model combined the approach of Helmholtz and the Guoy-Chapman theory and eliminated the consideration of the ions as point charges. This model proposed that the Gouy-Chapman diffuse double-layer starts a distance $\mathrm{x}_{2}$ (in Figure 2.4) away from 
the electrode. As a consequence, the interfacial capacitance in this model is composed of two series connected capacitances which are the constant Helmholtz capacitance and the Gouy-Chapman capacitance which increases as the concentration of the electrolyte increases. $^{15}$

\subsubsection{Pseudo-Capacitance}

Pseudo-capacitance involves a completely different charge storage mechanism which is faradaic in nature and requires charge transfer across the electrode/electrolyte interface. The faradaic process involves two types of reaction. One is the redox reaction which occurs in the metal oxide or conducting polymer electrodes, the other is the adsorption of ions on the electrode surface from the electrolyte. This capacitance behavior was first noted by Buzzanca and Tarasatti in the cyclic voltammetry behavior of $\mathrm{RuO}_{2}$ electrodes and followed by the studies of Conway et al., on under potential deposition of hydrogen ad-atom. ${ }^{16,17}$

\section{a) Redox reaction}

The electrochemical potential, E, of a redox reaction involving an oxidant, ox, and reductant, red, can be calculated using the Nernst equation at $25^{\circ} \mathrm{C}$ (eqn. 2.5).

$$
O \mathrm{x}+\mathrm{ne}^{-} \rightarrow \operatorname{Red}
$$

The potential, $E$, is given by eqn $2.6, \mathrm{E}^{0}$ is the standard electrode potential and $\mathrm{z}$ is the no. of moles of electrons involved in the process. $\mathrm{a}_{\mathrm{Red}}$ and $\mathrm{a}_{\mathrm{Ox}}$ are the activity coefficients of reductant and oxidant in the reaction. 


$$
E=E^{0}-\frac{0.05916 \mathrm{~V}}{\mathrm{z}} \log _{10} \frac{[\mathrm{Red}]}{[\mathrm{Ox}]}
$$

Researchers who did fundamental research on the metal oxide electrodes believed the extent of faradaic charge (q) passed in a surface redox process was a function of electrode potential. Hence the derivative, $\mathrm{dq} / \mathrm{dV}$, arises which is the capacitance of electrode. ${ }^{17}$

Table 2.1 summarizes the two capacitive behaviors.

Table 2.1.

Comparison of double-layer and pseudo-capacitance properties (taken from Conway et al.). ${ }^{17}$

\begin{tabular}{|c|c|}
\hline Double-layer Capacitance & Pseudo-Capacitance \\
\hline $\begin{array}{l}\text { - Involves non-faradaic process } \\
\text { - Capacitance has the value of } 20 \\
\text { to } 50 \mu \mathrm{F} / \mathrm{cm}^{2} \\
\text { - Capacitance is fairly constant } \\
\text { with potential } \\
\text { - Highly reversible nature of } \\
\text { charging and discharging }\end{array}$ & $\begin{array}{l}\text { - Involves faradaic process } \\
\text { - Capacitance has the value of } \\
2000 \mu \mathrm{F} / \mathrm{cm}^{2} \\
\text { - Capacitance is not constant } \\
\text { with potential } \\
\text { - Quasi - reversible nature } \\
\text { charging and discharging } \\
\text { depends on faradaic resistance } \\
\mathrm{R}_{\mathrm{f}}\end{array}$ \\
\hline
\end{tabular}




\subsection{Classification of Electrochemical Capacitors}

Electrochemical capacitors can be classified as to the processes involved in the capacitor.

- Electrochemical Double-layer Capacitor (EDLC)

- Pseudo-capacitor

- Hybrid Capacitor

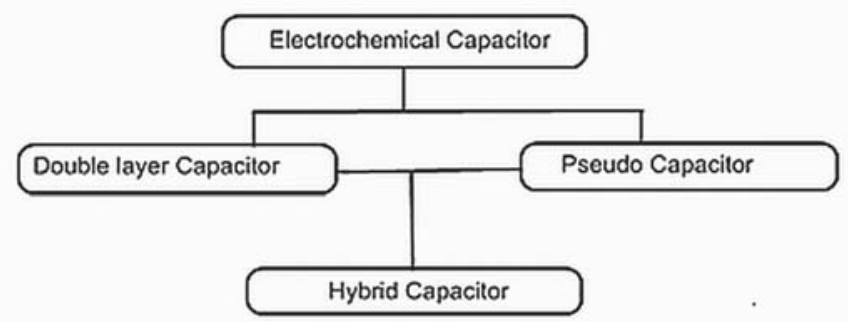

Figure 2.7. Flow-chart describing the different types of capacitors. ${ }^{18}$

EDLC's employs high surface area carbons, carbon aerogels, carbon fibers and carbon nanotubes. The pseudo-capacitor utilizes the metal oxides such as $\mathrm{RuO}_{2}, \mathrm{NiO}$ and $\mathrm{MnO}_{2}$. Hybrid capacitors make use of high surface area carbon electrodes in combination either with battery type redox electrodes such as nickel hydroxide and lithium electrodes or pseudo-capacitor type electrodes. 


\subsection{Literature Review on Electrochemical Capacitors}

\subsubsection{Electrochemical Double-Layer Capacitance}

Carbon has been a widely used material for electrochemical capacitor applications. The properties such as different allotropes, variety of dimensionality, and the cost effective nature make carbon undoubtedly an attractive material for electrochemical energy storage.

\section{a) Activated Carbon}

Activated carbons are well studied materials for capacitor applications. . The purpose of the activation process is to develop a high surface area on the order of 2000 $\mathrm{m}^{2} / \mathrm{g}$, with a controlled distribution of pores. ${ }^{19}$ Theoretically, the higher the surface area the material, the higher the specific capacitance. Shi, et al., have done extensive studies on different activated carbons to see the relation of the BET surface area and the pore size on the specific capacitance of the carbon materials. ${ }^{20}$ Table 2.2 summarizes these measurements for various carbons. The results showed that there is no linear relationship between these properties and the capacitance. They also reported that the specific capacitance strongly depends on the porous structure of the material in organic electrolyte. They concluded that the accessibility of pores is the important parameter which determines the capacitance. In view of this study, if the electrolyte solution contains bigger solvated ions having the size of 2 to $5 \mathrm{~nm}$ such as $\mathrm{BF}_{4}^{-}$and $\left.\left(\mathrm{C}_{2} \mathrm{H}_{5}\right)_{4} \mathrm{~N}^{+}\right)$, in propylene carbonate and the electrode contains small, non-accessible pores $(<2 \mathrm{~nm}$ diameter $)$ then these smaller pores will not contribute to the total double-layer capacitance of the material. On the other hand, in aqueous electrolyte solution the pores less than $0.5 \mathrm{~nm}$ could not be accessed electrochemically. Depending on the electrolytic medium, the carbon material with the appropriate porosity should be selected to optimize the capacitance. ${ }^{20}$ 
Table 2.2.

The properties of various carbon materials including capacitance (taken from Shi, et al.). ${ }^{20}$

\begin{tabular}{|c|c|c|c|c|c|}
\hline Carbon & $\begin{array}{c}\frac{\text { Specific }}{\text { capacity }} \\
\text { (F/g) }\end{array}$ & $\begin{array}{l}\frac{\text { Specific }}{\text { capacity }} \\
\underline{\left(\mathrm{F} / \mathrm{cm}^{2}\right)}\end{array}$ & $\begin{array}{l}\text { BET } \\
\left(\mathrm{m}^{2} / \mathrm{g}\right) \\
\end{array}$ & $\begin{array}{l}\underline{\text { Pore }} \\
\text { Volume } \\
\text { (cc/g) }\end{array}$ & $\underline{\text { Pore Size }}$ \\
\hline M-10 & 55.95 & 0.041 & 1370 & 0.5 & 9.12 \\
\hline M-14 & 57.20 & 0.0047 & 1223 & 0.561 & 9.60 \\
\hline M-15A & 78.10 & 0.043 & 1800 & 0.629 & 9.17 \\
\hline M-15B & 55.80 & 0.034 & 1624 & 0.563 & 9.37 \\
\hline $\mathrm{M}-15 \mathrm{C}$ & 63.34 & 0.042 & 1518 & 0.6 & 9.79 \\
\hline M-20 & 100 & 0.046 & 2130 & 0.71 & 14.73 \\
\hline M-30 & 32.9 & 0.024 & 2571 & 1.23 & 14.95 \\
\hline A-10 & 35.3 & 0.031 & 1150 & 0.424 & - \\
\hline A-20 & 41.20 & 0.020 & 2012 & 0.902 & 14.23 \\
\hline SACF-20 & 48.8 & 0.027 & 1839 & 0.699 & 9.74 \\
\hline
\end{tabular}

\section{b) Carbon Aerogels}

Carbon aerogels are a monolithic, 3D mesoporous network of carbon nanoparticles, which were also considered as promising materials for electrochemical capacitor applications. Carbon aerogels can be synthesized by the sol-gel process in which the researchers employed organic aerogels contains resorcinol-formaldehyde (RF) or phenol-furfural $(\mathrm{PF})$ as a starting material. The performance of these materials is strongly relied on the preparation process. The pyrolysis temperature and the reactant/catalyst ratio determine the texture and pore distribution of carbon aerogels. ${ }^{21}$

Scientists at Lawrence Livermore National Laboratory (LLNL), have developed a unique family of open-cell carbon aerogel foams. They have performed a comprehensive study of this material, demonstrating its potential for a high power and high energy density electrochemical capacitor. ${ }^{22}$ Pekala, et al., examined the structure-electrochemical property relationship of carbon aerogel monoliths and composites used in electrochemical devices. 
They found that there is a strong correlation between the textures of carbon aerogels and the specific capacitance as it was in the case of activated carbon materials. They also synthesized carbon aerogel nanostructure and studied the specific capacitance in various electrolyte composition. ${ }^{23}$ Saliger et al., synthesized carbon aerogel under high temperature process and showed that the carbon aerogel obtained at temperatures over $900^{\circ} \mathrm{C}$ possesses an increase in specific capacitance. They also reported that, a heat treatment at $500^{\circ} \mathrm{C}$ in air induced functionalization on the carbon surface which caused a significant improvement of the capacitance through the pseudo-capacitance effects. ${ }^{24}$

\section{c) Carbon Nanotubes}

In recent years researchers have shown tremendous interest in Carbon Nanotubes (CN) for electrochemical capacitor application. Diu, et al., synthesized unique $\mathrm{CN}$ sheet electrodes which have a high purity and narrow diameter distribution using a Pt catalyst. They demonstrated the use of that material in high power density $(>8000 \mathrm{~W} / \mathrm{kg}$ ) applications. ${ }^{25}$ In comparison with other carbon materials, carbon nanotubes have a higher rate of electron transfer. This is due to their entangled network and the central canal in their structure which allows easy access of the ions to the electrode/electrolyte interface. and hence an increase in capacitance. Various authors have used Multi-Walled Nano Tubes (MWNTs) and Single-Walled NanoTubes (SWNTs) for electrochemical capacitor application. ${ }^{20}$ Among them, An, et al., investigated the parameters which determine the performance of SWNT electrodes in electrochemical capacitors. They obtained a maximum specific capacitance of $180 \mathrm{~F} / \mathrm{g}$ with a large power density of $20 \mathrm{~kW} / \mathrm{kg}$ at an energy density of $6.5 \mathrm{Wh} / \mathrm{kg}^{26}$ 


\subsubsection{Pseudo-Capacitors}

\section{a) Metal Oxide Capacitor}

Zheng, et al., characterized the hydrous form of ruthenium oxide $\left(\mathrm{RuO}_{2} \cdot \mathrm{xH}_{2} \mathrm{O}\right)$ for EC capacitor application. ${ }^{27}$ The study showed excellent electrode performance of that material in electrochemical capacitors. This material, as prepared by a sol-gel process at low temperatures, is amorphous and electrically conductive. The specific capacitance is over $720 \mathrm{~F} / \mathrm{g}$. Although this $\mathrm{RuO}_{2}$ based capacitor gave huge specific capacitance, it is practically limited due to high cost and toxic nature. In view of searching an inexpensive alternate to $\mathrm{RuO}_{2}$, Tsai, et al., synthesized $\mathrm{MnO}_{2}$ using chemical and electrochemical processes, and characterized the capacitance performance. ${ }^{28}$ Nickel oxide synthesized by a sol-gel method ${ }^{29}$ and an electrochemical method ${ }^{30}$ was found to give a pseudo-capacitance value of 50-65 F/g. Cobalt oxide prepared by a sol-gel process was also suggested for EC capacitor applications. $^{31}$

\section{b) Conducting Polymers}

Conducting polymers have been considered as yet another promising pseudocapacitive material. These materials undergo redox type reaction during EC capacitor operation and contribute pseudo-capacitance. Several advantages as well as drawbacks accrue to this material over other systems. The good intrinsic conductivity, ease of preparation and relatively low cost are some of the advantages, and the poor stability, high volumetric change during the insertion/de-insertion process, and the ability to undergo swelling during operation are the major disadvantage of this material. Among the conducting polymeres, polyaniline (PANI) has received much attention due to its higher 
environmental stability, controllable electrical conductivity, and easy processability. ${ }^{32}$ The application of conducting polymers as electrochemical capacitors is described in the literature. ${ }^{33-35}$ They all suggested that the electrochemical activity of conducting polymers is determined by its working potential range, polymer degradation and over charging.

\subsubsection{Hybrid Capacitor}

The two most studied rechargeable, faradaic electrode components for hybrid capacitor applications are $\mathrm{PbO}_{2} / \mathrm{PbSO}_{4}$ and $\mathrm{NiOOH} / \mathrm{Ni}(\mathrm{OH})_{2}$. The negative electrodes in these hybrid capacitors were fabricated using different carbon materials such as activated carbon, carbon nano-fibers and activated carbon cloth. ${ }^{36}$

Zheng, et al., developed a model for calculating the maximum theoretical energy density and swing voltage in hybrid cells. ${ }^{37}$ They correlated the mass ratio of the positive to negative electrode to the obtained energy density. They also studied the cell performance in different electrolytes and showed the strong influence of electrolyte on the energy density of the cell. They proposed that in any hybrid cell with carbon and faradic electrodes, the maximum energy density is mainly determined by the specific capacitance of the carbon electrode. They experimentally achieved an energy density of $41 \mathrm{Wh} / \mathrm{kg}$ (or $77 \mathrm{Wh} / \mathrm{L}$ ) from their asymmetric cell containing nickel electrodes and activated carbon with a specific capacitance of $200 \mathrm{~F} / \mathrm{g}$. They extended the model to calculate energy density and swing voltage in other hybrid cell systems. Zheng, et al. assumed that the voltage swing in the capacitor is entirely due to the capacitor electrode and showed that the cell performance is dependent upon the mass ratio of the two electrodes. Because of this assumption these 
models were inaccurate in describing the rate dependant charge/discharge behavior of asymmetric cells. The results are summarized in Table 2.3.

Table 2.3.

This table summarizes the performance parameters for the five capacitor systems studied by Zheng, et al. ${ }^{37}$

\begin{tabular}{|c|c|c|c|c|c|}
\hline $\begin{array}{c}\text { Type of Cell } \\
\text { Cathode /anode }\end{array}$ & $\frac{\begin{array}{c}\text { Specific } \\
\text { Capacitance }\end{array}}{\underline{\text { (Specific }}}$ & Electrolyte & $\underline{\text { Voltage }(\mathrm{V})}$ & $\begin{array}{l}\frac{\text { The }}{\text { Maximum }} \\
\underline{\text { Energy }} \\
\text { Density } \\
\underline{(\mathrm{Wh} / \mathrm{Kg})}\end{array}$ & $\frac{\frac{\text { Mass }}{\text { Distribution }}}{\frac{\text { Cathode }}{\text { /Anode/ }}}$ \\
\hline $\begin{array}{l}\text { Carbon/ } \\
\text { Carbon }\end{array}$ & $280 \mathrm{~F} / \mathrm{g}$ & $\begin{array}{c}5.26 \mathrm{M} \\
\mathrm{H}_{2} \mathrm{SO}_{4} \text { in } \\
\mathrm{H}_{2} \mathrm{O}\end{array}$ & 1.0 & 7.16 & $1 / 1 / 0.72$ \\
\hline $\begin{array}{l}\text { Carbon/ } \\
\text { Carbon }\end{array}$ & $120 \mathrm{~F} / \mathrm{g}$ & $\begin{array}{c}\mathrm{Et}_{4} \mathrm{NBF}_{4} \text { in } \\
\mathrm{PC}\end{array}$ & 3.0 & 9.41 & $1 / 1 / 5.97$ \\
\hline $\begin{array}{l}\mathrm{RuO}_{2} \cdot \mathrm{xH}_{2} \mathrm{O} / \\
\mathrm{RuO}_{2} \cdot \mathrm{xH}_{2} \mathrm{O}\end{array}$ & $768 \mathrm{~F} / \mathrm{g}$ & $\begin{array}{c}5.26 \mathrm{M} \\
\mathrm{H}_{2} \mathrm{SO}_{4} \text { in } \\
\mathrm{H}_{2} \mathrm{O}\end{array}$ & 1.0 & 26.7 & $1 / 1$ \\
\hline $\begin{array}{c}\text { Carbon/ } / \mathrm{WO}_{2} \\
\mathrm{Li}_{4} \mathrm{Ti}_{5} \mathrm{O}_{12}\end{array}$ & $\begin{array}{c}120 \mathrm{~F} / \mathrm{g} \\
(168 \mathrm{~mA} / \mathrm{g})\end{array}$ & $\begin{array}{c}1 \mathrm{M} \mathrm{LiPF}_{6} \\
\text { in } 2 \mathrm{EC}: \\
\mathrm{DMC}\end{array}$ & 3.2 & 34.51 & $3.34 / 1 / 7.16$ \\
\hline $\begin{array}{l}\mathrm{Ni}(\mathrm{OH})_{2} / \\
\text { Carbon }\end{array}$ & $\begin{array}{l}292 \mathrm{~mA} / \mathrm{g} \\
(280 \mathrm{~F} / \mathrm{g})\end{array}$ & $\begin{array}{c}6.25 \mathrm{M} \\
\mathrm{KOH} \text { in } \\
\mathrm{H}_{2} \mathrm{O}\end{array}$ & 1.65 & 50.35 & 1/3.3./1.97 \\
\hline
\end{tabular}

Lang, et al., stabilized $\alpha-\mathrm{Ni}(\mathrm{OH})_{2}$ by substituting $7.5 \%$ aluminum and assembled asymmetric capacitor using activated carbon as negative electrode with a specific surface area of $2000 \mathrm{~m}^{2} / \mathrm{g}$ (and a diameter of 5-10 $\mu \mathrm{m}$ ). Their asymmetric capacitor showed a maximum specific capacitance of $127 \mathrm{~F} / \mathrm{g}$ and a specific energy of $42 \mathrm{Wh} / \mathrm{kg}$ in an alkaline $\mathrm{KOH}$ electrolyte (based on negative electrode mass only). ${ }^{3}$

Wang, et al., synthesized $\mathrm{Ni}(\mathrm{OH})_{2} /$ multiwalled carbon nanotube (MWNT) nanocomposites in an alkaline solution. They studied the effects of the amount of carbon 
nanotubes on the electrochemical capacitance of $\mathrm{Ni}(\mathrm{OH})_{2}$. The hybrid capacitor was assembled with a $\mathrm{Ni}(\mathrm{OH})_{2} / \mathrm{MWNT}$ composite as a positive electrode and activated carbon as a negative electrode that delivered a specific energy of $32 \mathrm{Wh} / \mathrm{kg}$ at a specific power of $1500 \mathrm{~W} / \mathrm{kg}$. It also exhibited good cycling performance and kept $90 \%$ of its initial capacity for over 2000 cycles. $^{38}$ Scientist also tried to utilize the lithium based electrode for this application. Glenn, et al., utilized activated carbon and a nanostructured $\mathrm{Li}_{4} \mathrm{Ti}_{5} \mathrm{O}_{12}$ as the positive and negative electrode, respectively to assemble a non-aqueous hybrid cell that exhibits a sloping voltage profile from 3 to $1.5 \mathrm{~V}, 90 \%$ capacity utilization at $10 \mathrm{C}$ charge/discharge rates, and 10-15\% capacity loss after 5000 cycles. $^{26}$ Aurelien, et al., designed a group of different cells. They coupled activated carbon and different lithium battery cathodes including $\mathrm{LiCoO}_{2}$, and $\mathrm{LiMn}_{2} \mathrm{O}_{4}$. They also assembled a conventional carbon-carbon supercapacitor, and Li-ion battery using nanostructured $\mathrm{Li}_{4} \mathrm{Ti}_{5} \mathrm{O}_{12}$ as an anode to compare the performance of these different cells. Acetonitrile electrolyte containing a lithium salt was used as electrolyte in all the cells. They compared the performance characteristics of the cells to find the effect of cell components on cell properties such as the specific energy, specific power, charge rate capability, low temperature operation, cycle-life and self-discharge. Their results showed that two components, activated carbon and acetonitrile made significant performance improvements between those devices. The use of activated carbon cathodes (or not) impacted the length of cycle-life. The acetonitrile based electrolyte enhanced the rate capability and leads to improved low-temperature performance. ${ }^{39}$ 


\section{METHODS AND CHARACTERIZATION TECHNIQUES}

\subsection{Materials and Reagents}

Nickel (II) nitrate hexa-hydrate, $\mathrm{Ni}\left(\mathrm{NO}_{3}\right)_{2} \cdot 6 \mathrm{H}_{2} \mathrm{O}, 99 \%$ pure, cobalt (II) nitrate hexahydrate, $\mathrm{Co}\left(\mathrm{NO}_{3}\right)_{2} \cdot 6 \mathrm{H}_{2} \mathrm{O}, 99 \%$ pure, and potassium hydroxide, $\mathrm{KOH}, 85 \%$ pure, were obtained from Sigma Aldrich. $\dagger$ Carbon foams were purchased from POCOFoam ${ }^{\circledR}$ (which has a lower density and higher total porosity than POCO HTC foam). Acetone was used for cleaning the as received carbon foams. Carbon black (Ketjenblack EC-600JD) manufactured by Akzo Nobel Polymer Chemical, LLC ${ }^{\S}$ was used for the negative electrode. PTFE, 60 wt. \% dispersed in water (DuPont $6 \mathrm{C} \dagger$ ) was used as binder. Celgard $3501^{\circledR} *$ was used. De-ionized water was used for preparing all the chemicals.

\subsection{Positive Electrode Synthesis}

Cathodic deposition is a widely used process for depositing $\alpha$-nickel hydroxide into nickel plaque and more recently into carbon foam. ${ }^{4}$ It provides good bonding between current collector and active materials and increases the conductivity of the electrodes. Hence the electro-deposited electrodes yield superior performance with high material utilization and long cycle life.

* Celgard, LLC, 13800 South Lakes Dr, Charlotte, NC 28273.

\$Poco Graphite, Inc., 300 Old Greenwood Rd., Decatur, Texas 76234.

$\S$ Akzo Nobel Coatings Inc, 20 Culvert Street, Nashville, Tennessee TN 37210

† Sigma Aldrich, PO Box : 14508, St.Louis, MO- 63178. 
By controlling current density and the concentration of nickel nitrate in this process it is possible to selectively control the structure and non-stochiometry of the $\alpha-\mathrm{Ni}(\mathrm{OH})_{2}$. In addition to this, the cathodically deposited $\alpha-\mathrm{Ni}(\mathrm{OH})_{2}$ has similar layer stacking (ABBCCA) to that of the defective non-stoichiometric structure. Therefore, this defective active mass can be readily "formed." (B. C. Cornilsen, personal communication). Cathodic deposition of nickel hydroxide in nickel nitrate solution involves two major steps

1) The electrochemical reduction of aqueous nickel nitrate ions according to reaction 3.1, and

2) Precipitation of nickel hydroxide (eqn. 3.2) due to the steep increase in $\mathrm{pH}$ at the electrode surface caused by the hydroxyl ions generated in eqn. 3.1.

$$
\begin{gathered}
\mathrm{NO}_{3}{ }^{-}+\mathrm{H}_{2} \mathrm{O}+2 \mathrm{e}^{-} \rightarrow \mathrm{NO}_{2}{ }^{-}+2 \mathrm{OH}^{-} \quad \mathrm{E}^{0}=0.01 \mathrm{~V} \\
\mathrm{Ni}_{2}{ }^{+}+2 \mathrm{OH}^{-} \rightarrow \mathrm{Ni}(\mathrm{OH})_{2} \downarrow
\end{gathered}
$$

In this study cathodic deposition was performed using an Arbin potentiostat* model no. BT2000. The temperature of the electrolyte bath was controlled by a thermostat (Neslab RTE-140) and the deposition was carried out at $70^{\circ} \mathrm{C}$. Carbon foam was punched out in a circular shape of diameter $2.182 \mathrm{~cm}$ and $1.52 \mathrm{~cm}$ thickness. Foams were sonicated with acetone for sixty minutes to remove the debris from the surface. After sonication the foams were dried in air over night to remove all the remaining solvent. These foams were used as the cathode and two nickel foils were used as a counter electrode on both sides of the

*Arbin Instruments, 762 Peach Creek Cut Off Road, College station, TX-77845 
cathode in order to uniformly distribute the current density. The deposition solution consisted of $1.8 \mathrm{M} \mathrm{Ni}(\mathrm{NO})_{3}$ and $12.5 \mathrm{wt} \%$ of $\mathrm{Co}(\mathrm{NO})_{3}$ dissolved in $45 \mathrm{wt} \%$ aqueous ethanol. The de-ionized water was boiled so as to remove the dissolved $\mathrm{CO}_{2}$ and used for solution preparation. A current density of $100 \mathrm{~mA} / \mathrm{cm}^{2}$ and a deposition time of 55 minutes were employed for all the depositions. After deposition the electrodes were thoroughly washed with water to remove remaining nitrate solution.

\subsection{Forming Process}

In order to condition/activate the prepared positive electrode, the forming process was carried out in $26 \mathrm{wt} \% \mathrm{KOH}$ electrolyte. A cell was assembled using the deposited nickel hydroxide as the positive electrode, nickel foil as a counter electrode and $\mathrm{Hg} / \mathrm{HgO}$ (20 wt $\% \mathrm{KOH}$ ) was used as reference electrode. The forming process consisted of a total of five charge and discharge cycles. The first cycle was carried out at a higher current density of $70 \mathrm{~mA} / \mathrm{cm}^{2}$. The electrode was charged for sixty minutes and discharged to $0.15 \mathrm{~V}$ (w.r.t. $\mathrm{Hg} / \mathrm{HgO}$ ). From the second cycle onwards the current density and the charging time were reduced to $20 \mathrm{~mA} / \mathrm{cm}^{2}$ and 45 minutes, respectively. The discharge was carried out in these cycles until the voltage droped to the cutoff potential, ie., $0.15 \mathrm{~V}$ (w.r.t. $\mathrm{Hg} / \mathrm{HgO}$ )

The complete forming of the electrode was identified by a stable charge/discharge curve profile at the end of fifth cycle. It is worth mentioning that depending on the amount of active material loaded into the carbon foam electrode, the current density used in the forming process will vary and will be defined for each example. 


\subsection{Negative Electrodes}

Negative electrodes were made by Jinjin Wang with carbon black (Ketjenblack EC600JD). The electrode composition was set to be $90 \%$ carbon black and $10 \%$ binder (PTFE 60 wt. \% dispersed in water). The materials were weighed based on this composition and ground uniformly in a mortar. After grinding, the mortar was placed in the oven at $120^{\circ} \mathrm{C}$ for thirty minutes. The contents were mixed again and then heated for another thirty minutes at $120^{\circ} \mathrm{C}$. After that, $3 \mathrm{ml}$ of isopropanol and $3 \mathrm{ml}$ of ethanol were added to the mixture to aid the dough formation. The dough was flattened on a glass sheet using a glass rod. Circular electrodes were punched out from the sheet and the then dried under vacuum for two hours to allow the binder to evaporate.

\subsection{Cell Assembly}

After the preparation of electrodes, a cell was assembled for electrochemical characterization; a PFA (Poly Fluoro Acetylene) Swagelok-type fitting, purchased from McMaster $^{\circledR} *$, was constructed (see Fig. 3.1). The separator was sandwiched between the positive and the negative electrodes in the cell. Care should be taken to avoid a short circuit between the electrodes. The stainless steel connectors were placed in each side of the cell and firmly tightened. Then the cell was filled with electrolyte $(3 \mathrm{ml})$ and mounted horizontally in the clamp for electrochemical characterization. Table 3.1 lists the components of the Swagelok-type PFA cell. A completely fabricated cell is shown in Fig.

\section{2 .}

\footnotetext{
* McMaster-Carr, 600N County Line Rd, Elmhurst, IL-60126
} 


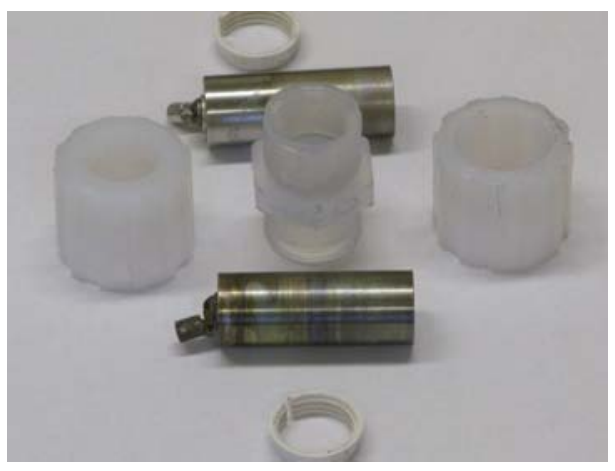

Figure 3.1. The components of a Swagelok-type PFA cell (photograph by author).

Table 3.1.

The components of a Swagelok-type PFA cell.

\begin{tabular}{|c|c|}
\hline Current collector & Nickel screen \\
\hline Positive material & Nickel hydroxide \\
\hline Negative material & Ketjenblack (carbon black) \\
\hline Binder & $10 \mathrm{wt}$ \% PTFE/C \\
\hline Separator & Celgard 3501 \\
\hline Electrolyte & $26 \mathrm{wt} \% \mathrm{KOH}(\mathrm{aq})$ \\
\hline
\end{tabular}

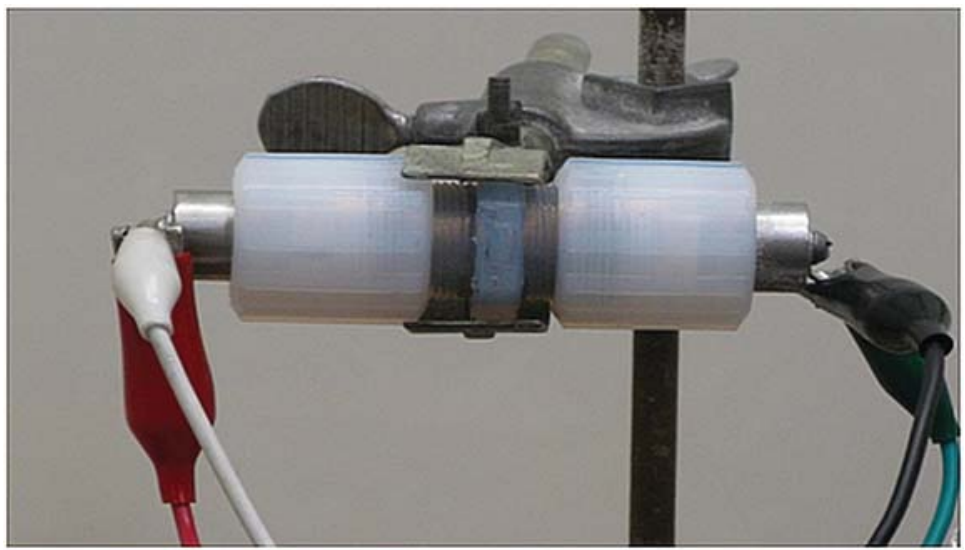

Figure 3.2. Assembled Swagelok-type PFA cell (photograph by author). 


\subsection{Electrochemical Characterization}

\subsubsection{Cyclic Voltammetry}

Cyclic voltammetry is a preferred technique for initial screening of materials for electrochemical capacitor applications. The major advantage comes from the ability of this technique to provide detailed information about the capacitance and its voltage

dependence, power characteristics, and the reversibility of the electrochemical reaction. ${ }^{40}$ Consider an electrochemical cell in which there is no redox couple available to undergo faradic reaction. We can adequately describe that electrode interface in the cell with the use of the parallel-plate double-layer capacitor model. When the electrode is subjected to a potentio-dynamic condition (i.e., an increasing potential), a transient current can flow because of ionic motion in the electrolyte to the electrode to form the double-layer. The charge stored on the parallel plate capacitor, $\mathrm{q}$, is proportional to the voltage drop, E, across the plates (eqn. 3.3).

$$
\mathrm{q}=\mathrm{CE}
$$

The proportionality constant, $\mathrm{C}$, is the capacitance. The capacitance can be calculated if the geometry of the parallel plates and dielectric properties of the medium were known using equation 3.4 , where, $\varepsilon$, is the dielectric constant of the material separating the parallel plates, $\varepsilon_{0}$, is the permittivity of free space, $\mathrm{d}$, is the separation between the plates, and $\mathrm{A}$ is the area of the electrode (from equation 2.4).

$$
\frac{C}{A}=\frac{\varepsilon \varepsilon_{0}}{\mathrm{~d}}
$$

Capacitance is an important factor because it measures the ability to store the electric charge, and it gives rise to current during the charging of the capacitor. By 
differentiating equation 3.3 with respect to time, $\mathrm{t}$, and assuming that the capacitance is constant, eqn. 3.5 shows the charging current in a capacitor, dq/dt.

$$
\frac{d q}{d t}=C \frac{d E}{d t}
$$

Replacing dq/dt by the current, I, and identifying $\mathrm{dE} / \mathrm{dt}$ as the scan rate, $\mathrm{r}$, the expression for the charging current can be obtained (eqn. 3.6).

$$
\mathrm{I}=\mathrm{Cr}
$$

Thus by measuring the charging current at a given scan rate, the capacitance of the system can be measured. If there is no possibility for electron transfer between the solution and the electrode, this will be the only current observed, due to the double-layer charging.

In all the cyclic voltammetric studies, a ramp potential is employed between the reference and working electrode, and the current response is measured between the working and counter electrodes. Figure 3.3 represents the potential vs. current response of an EDLC capacitor. During the initial potential scan, a sharp rise in current due to rapid ionic movement in the electrolyte can be seen. As the scan continues, the current then reaches steady state. Upon reversal of the scan rate, the current changes sign, goes to zero as it depolarizes, and then polarizes in the opposite direction. An ideal parallel plate capacitor would display a rectangular shape in a CV plot.

However, most EDLC devices suffer due to internal resistance; hence they display distorted voltammograms with irregular peaks. Prominent peaks that can occur within narrow voltage windows are usually evidence of pseudo-capacitive behavior. ${ }^{17}$ 

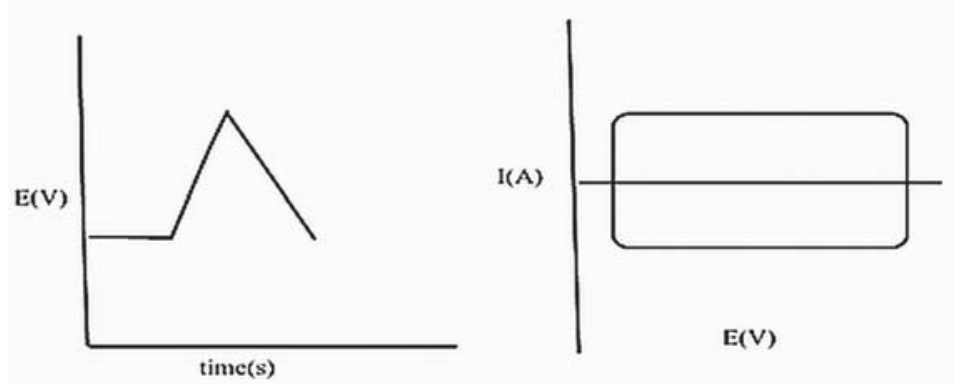

Figure 3.3. Cyclic voltammetric behavior of ideal capacitor.

Cyclic Voltammetry (CV) experiments also help to characterize the power performance of a capacitor. It is customary to plot different scan rates on the same plot to demonstrate the impact of power levels on the charging characteristics. For capacitor studies the experiment must be performed at faster sweep rates which are complimentary to charging and discharging the device at higher power levels. It is also observed that at higher scan rates the shape of the potential $v s$. current curve distorts drastically from the low scan rates.

Reversibility is the important parameter in all electrochemical systems. Cyclic voltammetry can also provide an indication of the degree of reversibility of an electrochemical reaction. By looking at the voltammograms we can see whether the reaction is reversible or not. A mirror-image voltammogram depicts a capacitor reaction that is reversible. 


\subsubsection{Constant Current Techniques}

A constant current charge/discharge experiment can be performed as a complementary procedure to the CV experiment. The experiment is carried out by applying a constant current between the working and auxiliary electrodes and recording the potential between the working and reference electrodes. Charging or discharging the cell at constant current results in a voltage response as opposed to the $\mathrm{CV}$ technique. The charge/discharge capacity $(\mathrm{Q})$ can be calculated by integrating the current with respect to time. The specific capacitance ( $\mathrm{SC}$ in $\mathrm{F} / \mathrm{g}$ ) can be measured from the discharge capacity and the voltage window using the formula in eqn. 3.7. The " 2 " arises because the cell capacitance is $1 / 2$ of the electrode capacitance.

$$
\operatorname{SC}\left(\frac{F}{g}\right)=C / m=\frac{2 Q}{\Delta V \times m}
$$

Constant current techniques also help to construct a Ragone plot. In this plot the energy density and power density are plotted against each other. Using this energy-power relation, different electrochemical power sources can be compared. For capacitance devices

the energy density and power density can be calculated using equations 3.8 and 3.9, where, $\mathrm{V}$ is voltage $(\mathrm{V})$, I is electric current $(\mathrm{A}), \mathrm{t}$ is time (s), and $\mathrm{m}$ is mass $(\mathrm{Kg})$.

$$
\begin{gathered}
\text { Energy Density }=\frac{\mathrm{V} \times \mathrm{I} \times \mathrm{t}}{\mathrm{m}} \\
\text { Power Density }=\frac{\mathrm{V} \times \mathrm{I}}{\mathrm{m}}
\end{gathered}
$$




\subsubsection{Electrochemical Impedance Spectroscopy}

Electrochemical Impedance Spectroscopy (EIS) is a popular characterization tool for studying the electrochemical reaction occurs at the electrode/electrolyte interface .The results from this technique contain rich information about the physiochemical process and the kinetics of electrochemical reaction. ${ }^{40}$ The advantages of this technique are, a) an ability to make measurement the frequency as well as in time domain., b) precise measurements are possible due to the latest advancements in modern electronic circuits, and, c) since we apply a small magnitude signal, in the range of a few milli-volts, the resulting system response may be indefinitely steady and can therefore be averaged over a long term.

The principle is the same for this technique as in the cyclic voltammetry. Instead of applying a small amplitude DC potential, here the system response is studied under a small amplitude AC signal of magnitude 5 to $10 \mathrm{mV}$. If the applied potential is in the sine wave form with characteristic magnitude, E, and frequency, $\omega, \mathrm{E}$ can be represented by, eqn. 3.10 .

$$
\mathrm{E}_{\mathrm{t}}=\mathrm{E}_{0} \sin (\omega \mathrm{t})
$$

$E_{t}$ is the potential at time $t, E_{0}$ is the amplitude of the signal, and $\omega$ is the angular frequency of the AC signal. The relationship between radial frequency $\omega$ (expressed in radians/second) and frequency $\mathrm{f}$ (expressed in hertz) is $\omega=2 \pi f$. The resultant current is also a sinusoidal wave which is phase shifted, $\theta$, depending on the nature of the interfacial region in the vicinity of the working electrode. This current, $\mathrm{I}_{\mathrm{t}}$, can be described by eqn. 3.11 .

$$
I_{t}=I_{0} \sin (\omega t+\theta)
$$


In electrical engineering these two quantities, voltage and current, can be viewed as two phase vectors (phasors) which have amplitude, either E or I, and frequency $\omega$ with an angle of rotation $\theta$.

Let us apply these concepts to the analysis of some simple circuits. Consider first a pure resistance, $R$, across which a sinusoidal voltage, $E_{t}=E_{0} \sin (\omega t)$, is applied. Since Ohm's law, $E=I R$, always holds, the current $I$ is $\left(E_{t} / R\right) \sin (\omega t)$, and it has the same phase as the voltage, meaning the phase angle is zero, as shown in Fig. 3.4

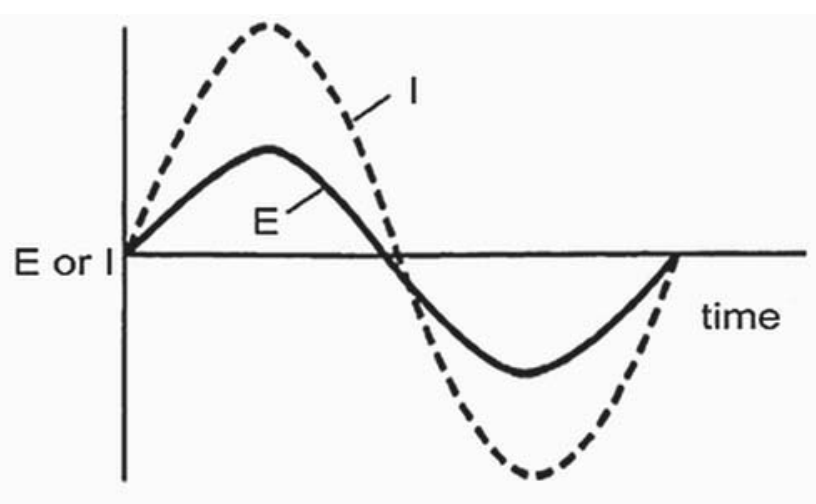

Figure 3.4. Current and voltage response of AC signal for a resistor. ${ }^{40}$

Now we can apply those concepts to a pure capacitance, C. The fundamental relation of interest is then, eqn. 3.12 .

$$
\mathrm{q}=\mathrm{CE}
$$

The current flow in the capacitor can be calculated by differentiating eqn. 3.12 with respect to time to give eqn. 3.13 .

$$
\mathrm{dq} / \mathrm{dt}=\mathrm{C}\left(\mathrm{dE}_{\mathrm{t}} / \mathrm{dt}\right)
$$


The rate of change in charge is known as current, and by substituting eqn. 3.10 into equation 3.13 , eqn. 3.14 is obtained.

$$
\mathrm{I}=\omega \mathrm{CE} \cos (\omega \mathrm{t})
$$

Current, I, can also be represented using eqn. 3.11 where $\theta=\pi / 2$ for a capacitor as written in eqn. 3.15 and eqn. 3.16 , where $X_{c}=1 /(\omega C)$ is the capacitive reactance.

$$
\begin{aligned}
& I=\omega C E \sin (\omega t+\pi / 2) \\
& I X_{c}=E \sin (\omega t+\pi / 2)
\end{aligned}
$$

From equation 3.16 it is clear that the phase angle is $\pi / 2$ and the current leads the voltage in the capacitor, as shown in Fig.3.5.

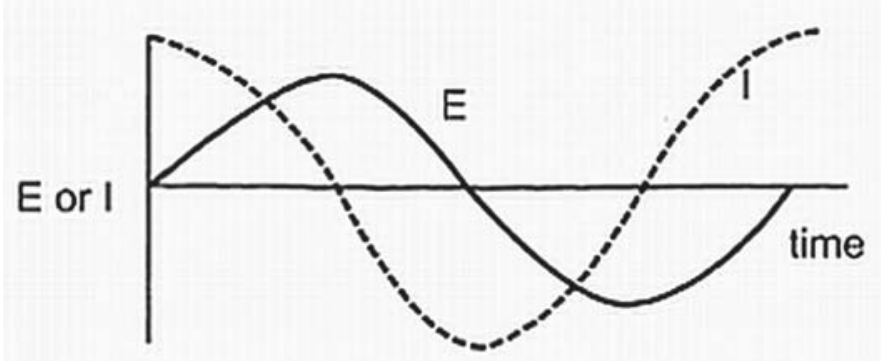

Figure 3.5. Current and voltage response of a capacitor for an AC signal. ${ }^{40}$

In electrical circuit analysis, it is customary to use complex notation $(j=\sqrt{-1})$ to plot these quantities. The current phasor is usually plotted along the abscissa and the 
voltage is plotted in the ordinate. By comparing equations 3.10 and 3.16 it is seen that the $\mathrm{AC}$ voltage in the capacitor leads the $\mathrm{AC}$ current in the capacitor by -90 degrees. In order to represent this behavior we can introduce the complex notation and with the help of complex number form the voltage can be represented as eqn. 3.17 (by dividing eqn. 3.15 by eqn. 3.16).

$$
E_{c}=-j X_{c} I
$$

A comparison of equation 3.17 to ohms law shows that $\mathrm{X}_{\mathrm{c}}$ must carry dimensions of resistance; but, unlike $R$, its magnitude falls with increasing frequency since $X_{c}=1 / \omega C$.

Now consider a series circuit which contains a resistance, $\mathrm{R}$, and a capacitance, $\mathrm{C}$. If we apply a voltage, $\mathrm{E}$, across the circuit, that voltage must equal the sum of the individual voltage drops across the resistor and the capacitor (eqn. 3.18). With eqn. 3.17 and $E=I R$ we obtain eqn.3.19 where we then define $Z$ (eqn.3.20).

$$
\begin{gathered}
E=E_{R}+E_{c} \\
E=I\left(R-j X_{c}\right) \\
E=I Z
\end{gathered}
$$

In this way if we plot current and voltage as vector quantities, the impedance comes out as a resultant vector $\mathrm{Z}=R-\mathrm{j} X$. Figure 3-6 displays the relationship between these quantities. In general the impedance can be represented as written in eqn.3.21, in terms of real and imaginary parts, $Z_{\mathrm{Re}}$ and $Z_{\mathrm{Im}}$, respectively.

$$
\mathrm{Z}=\mathrm{Z}_{\mathrm{Re}}-\mathrm{j} \mathrm{Z}_{\mathrm{Im}}
$$




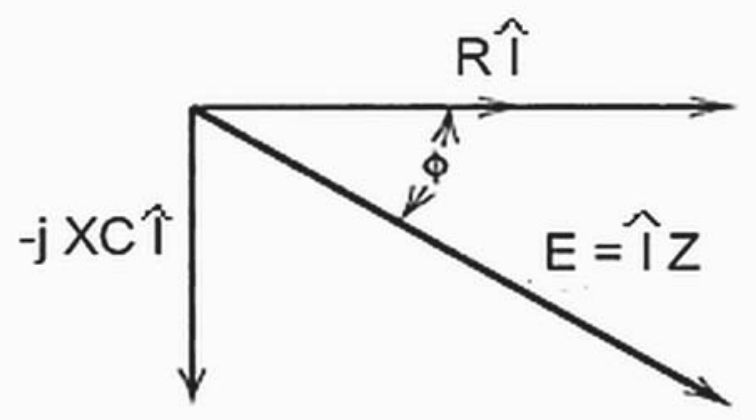

Figure 3.6. Current and voltage relation in the resistor and capacitor series circuit. $^{40}$

The magnitude of $Z$, written $|Z|$, is given by eqn. 3.22 and the phase angle, $\phi$, is given by eqn. 3.23 .

$$
\begin{gathered}
|\mathrm{Z}|=\mathrm{R}^{2}=\left(\mathrm{Z}_{\mathrm{Re}}\right)^{2}+\left(\mathrm{Z}_{\mathrm{Im}}\right)^{2} \\
\tan \phi=\mathrm{Z}_{\mathrm{Im}} / \mathrm{Z}_{\mathrm{Re}}=\mathrm{X}_{\mathrm{C}} / \mathrm{R}
\end{gathered}
$$

The phase angle represents the balance between capacitive and resistive components in the series circuit. For a pure resistance, $\phi=0$; for a pure capacitance, $\phi=$ $\pi / 2$; and for mixtures, intermediate phase angles are observed. The variation of the impedance with frequency can be displayed in two different ways. In a Bode plot, $\log$ of the modulus, $\log |Z|$, is plotted against phase angle $\phi$. In an alternative representation, a Nyquist plot, the real and imaginary impedance, $Z_{\mathrm{Im}} v s . Z_{\mathrm{Re}}$, are plotted for different values of $\omega$. 


\section{a) Equivalent circuit model:}

Electrochemical impedance spectroscopy is a valuable tool for modeling electrochemical phenomena which occurs at the electrode/electrolyte interface. These models are represented in terms of electrical circuit elements such as resistors, capacitors, and inductors to provide the system performance. Various authors have attempted to model the behavior of porous carbon electrodes and the associated double-layer capacitance using distributed networks of capacitors and resistors (see Fig. 3.7). ${ }^{41-43}$ Conway, et al., proposed an equivalent circuit for the electrochemical capacitor which includes pseudo-capacitance and double-layer capacitance (see Fig. 3.8). ${ }^{16,44}$ This circuit contains a series combination of faradaic resistance, $\mathrm{R}_{\mathrm{f}}$, and the pseudo-capacitance, $\mathrm{C}_{\Phi}$, in parallel with the double-layer capacitance, $C_{d l}$. $R_{2}$ is a potential-dependent leakage resistance in this circuit. $R_{s}$ is the solution resistance, and $\mathrm{L}$ is the inductance.

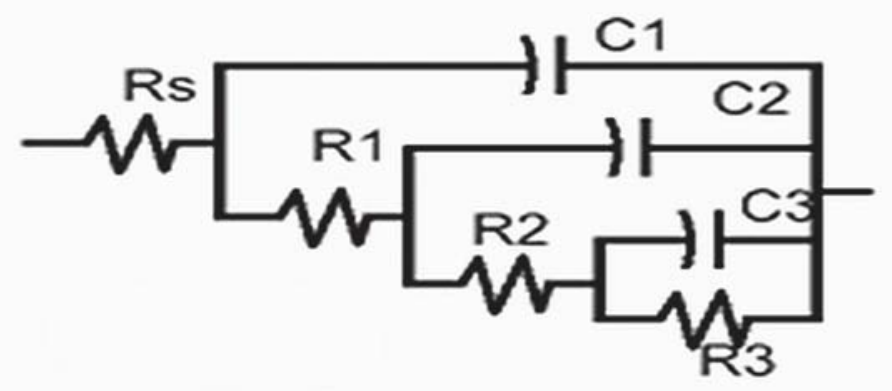

Figure 3.7. Ladder equivalent circuit for porous electrodes. $R_{s}$ is a solution resistance. 


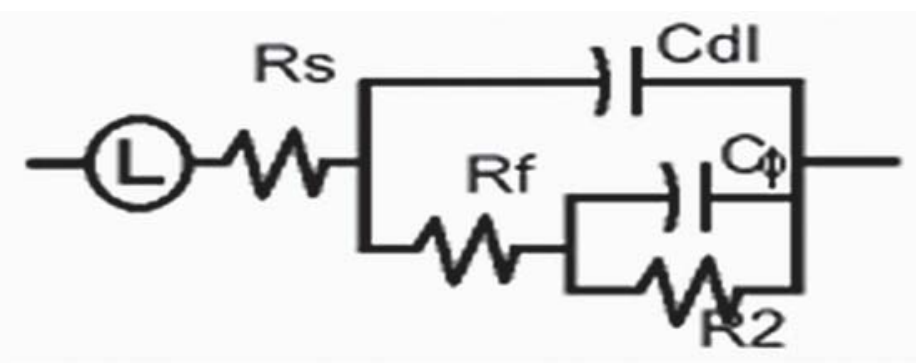

Figure 3.8. Conway's model circuit for an electrode with pseudocapacitance, $\mathrm{C}_{\Phi}$.

\section{b) Complex Power Analysis}

The figure of merit for an EC capacitor cell assembly can be obtained from its relaxation time constant. This parameter indicates the frequency at which the capacitor behaves like a pure capacitor. Generally an asymmetric capacitor has a higher relaxation time constant than a symmetric capacitor. The relaxation time constant can be found from a complex power vs. frequency analysis. This procedure was adapted from Taberna, et al. ${ }^{43}$ This method consists of the three steps.

First the resistive, $\mathrm{C}^{\prime}$, and reactive capacitance, $\mathrm{C}^{\prime \prime}$, can be calculated from the real and imaginary impedance at a particular frequency (equations 3.24 and 3.25), where $Z^{\prime}(\omega)$ and $Z^{\prime \prime}(\omega)$ are the respective real and imaginary parts of the complex impedance $Z(\omega) . \omega$ is the angular frequency, and it is given by $\omega=2 \pi \mathrm{f}$. Then the complex components of capacitance are expressed in equations 3.24 and 3.25 .

$$
\begin{aligned}
& C^{\prime}(\omega)=-Z^{\prime \prime}(\omega) / \omega[Z(\omega)]^{2} \\
& C^{\prime \prime}(\omega)=-Z^{\prime}(\omega) / \omega[Z(\omega)]^{2}
\end{aligned}
$$


The resistive and reactive capacitances can be converted to the resistive, $(\mathrm{P}(\omega)$, and reactive powers, $Q(\omega)$, at frequency $\omega$ (equations 3.26 and 3.27), where $\left|\Delta \mathrm{V}_{\mathrm{rms}}\right|^{2}=$ $\Delta V(\max ) / \sqrt{2}$ and $\mathrm{V}_{\max }$ is the maximum amplitude of the AC signal. The complex components of power are expressed in equations 3.26 and 3.27.

$$
\begin{gathered}
P(\omega)=\omega C^{\prime \prime}(\omega)\left|\Delta V_{\text {rms }}\right|^{2} \\
Q(\omega)=-\omega C^{\prime}(\omega)\left|\Delta V_{\text {rms }}\right|^{2}
\end{gathered}
$$

The normalized resistive, $\mathrm{P} / \mathrm{S}$, and reactive power, $\mathrm{Q} / \mathrm{S}$, are then plotted against the frequency. $\mathrm{S}$ is the modulus of $\mathrm{P}$ and $\mathrm{Q}, \mathrm{S}=\left(|\mathrm{P}|^{2}+|\mathrm{Q}|^{2}\right)^{1 / 2}$.

The impedance behavior of a capacitor shows pure resistor behavior at higher frequency and pure capacitance behavior at lower frequency. Hence the resulting complex power will vary in opposite directions and intersect at some point as the frequency is increased. The intersection where real and imaginary power are equal, $\mathrm{P}=\mathrm{Q}$, is known as the characteristic frequency of that capacitor. This defines the boundary between resistive and reactive behavior of an electrochemical capacitor. 


\section{RESULTS}

\subsection{Electrochemical Characterization of Symmetric Capacitor}

\subsubsection{Cyclic Voltammetry}

Cyclic voltammetry experiments are performed to analyze the capacitance behavior of the as-synthesized carbon sheet electrodes. For this purpose a symmetric cell was assembled with two carbon sheets per electrode $(1.92 \mathrm{~cm}$ diameter and $0.0505 \mathrm{~g} / \mathrm{sheet})$. Scans were performed at five different scan rates in the potential window between $-1.4 \mathrm{~V}$ and $1.4 \mathrm{~V}$ in 26 wt. \% KOH. Fig. 4.1 shows the potential vs. current response of the capacitor. Table 4.1 summarizes the cell specific capacitance (1/2 of eqn. 3.7, using discharge capacity from the Arbin file and $\Delta \mathrm{V}=2.8 \mathrm{~V}$ ) and columbic efficiency calculated at the respective scan rates.

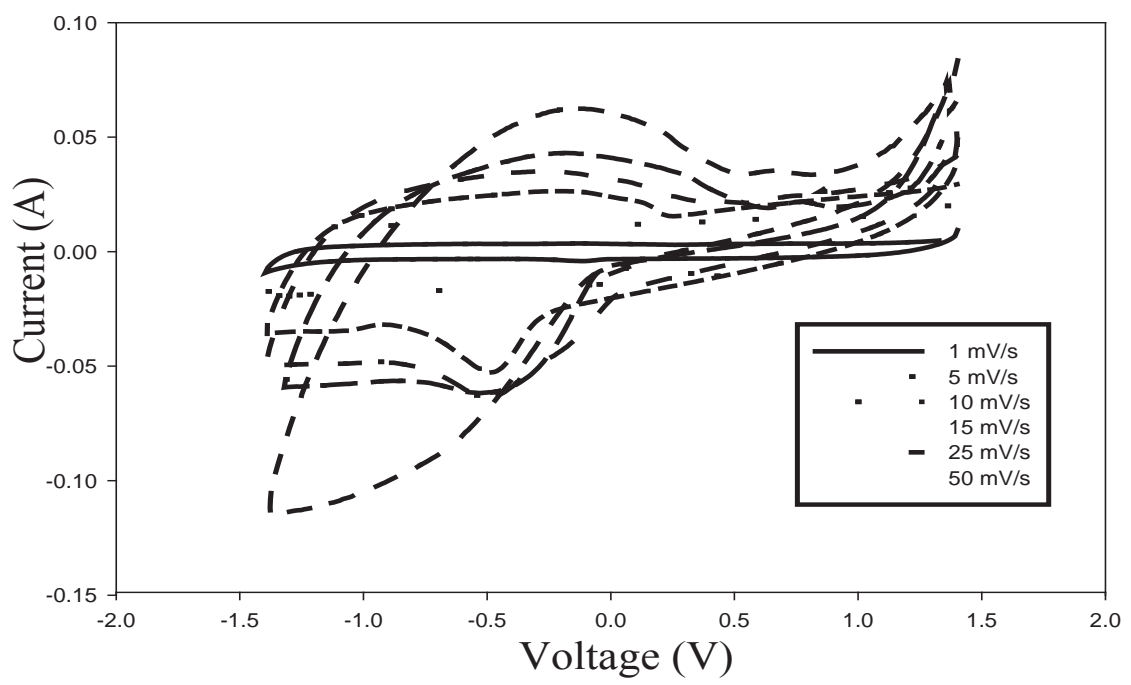

Figure 4.1. CV plot obtained at different scan rates in the symmetric capacitor (Swagelok-type PFA cell, Celgard 3501separator, 10\% $\mathrm{PTFE} /$ carbon black). 
Table 4.1.

Cell specific capacitance and columbic efficiency calculated for the symmetric capacitor, at six different CV scan rates (same cell as Fig. 4.1).

\begin{tabular}{|c|c|c|c|c|}
\hline$\frac{\text { Scan Rate }}{\underline{(\mathrm{mV} / \mathrm{s})}}$ & $\begin{array}{c}\text { Charge } \\
\text { Capacity (C) }\end{array}$ & 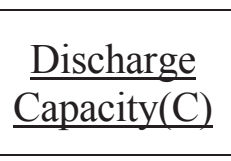 & $\frac{\text { Cell Specific }}{\frac{\text { Capacitance }}{(\mathrm{F} / \mathrm{g})}}$ & $\begin{array}{l}\frac{\text { Coulombic }}{\text { Efficiency }} \\
\frac{(\%)}{}\end{array}$ \\
\hline 1 & 9.02 & 9.09 & 32.15 & 101 \\
\hline 5 & 7.60 & 7.91 & 27.95 & 104 \\
\hline 10 & 6.36 & 6.23 & 22 & 98 \\
\hline 15 & 5.38 & 5.42 & 19.15 & 101 \\
\hline 25 & 4.51 & 4.57 & 16.2 & 101 \\
\hline 50 & 3.18 & 3.19 & 11.3 & 100 \\
\hline
\end{tabular}

\subsubsection{Constant Current Cycling}

Constant current charge/discharge cycling is performed to characterize the power performance of the carbon sheet electrodes and to obtain the energy density - power density relation for the symmetric capacitor device. The energy density-power density relation is constructed and represented in a Ragone plot. This experiment was performed at four different current densities: $0.35 \mathrm{~mA} / \mathrm{cm}^{2}, 0.88 \mathrm{~mA} / \mathrm{cm}^{2}, 1.75 \mathrm{~mA} / \mathrm{cm}^{2}$ and $3.55 \mathrm{~mA} / \mathrm{cm}^{2}$. Figure 4.2 shows the potential vs. time response of this capacitor. (The data plotted at each current density is from the $5^{\text {th }}$ of five cycles, and the experiment was started with the lowest current density.) Table 4.2 displays the capacitance, power density, and energy density calculated at four current densities. Figure 4.3 shows the Ragone plot. (This cell was not cycled to high numbers, only to 33 cycles) 


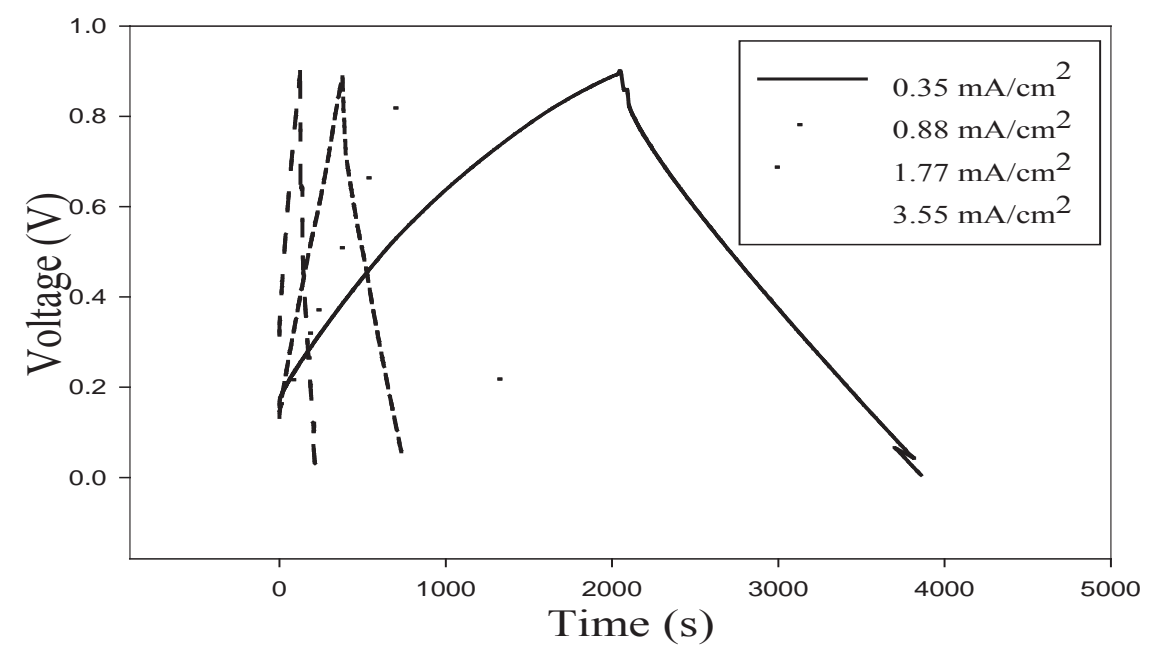

Figure 4.2. Potential vs. time response of the symmetric capacitor at different current densities (same cell as Fig. 4.1).

Table 4.2.

Cell specific capacitance, energy, and power density calculated at four different current densities (using equations 3.7, 3.8, and 3.9 respectively).

\begin{tabular}{|c|c|c|c|c|c|c|}
\hline $\begin{array}{l}\frac{\text { Current }}{\text { Density }} \\
\left(\mathrm{mA} / \mathrm{cm}^{2}\right) \\
\end{array}$ & $\begin{array}{l}\text { Charge } \\
\text { Capacity } \\
\text { (C) }\end{array}$ & $\begin{array}{l}\text { Discharge } \\
\text { Capacity } \\
\underline{(\mathrm{C})}\end{array}$ & $\begin{array}{l}\frac{\text { Specific }}{\text { Cell }} \\
\text { Capacitance } \\
\underline{(\mathrm{F} / \mathrm{g})}\end{array}$ & $\begin{array}{l}\frac{\text { Columbic }}{\text { Efficiency }} \\
\underline{(\%)}\end{array}$ & $\begin{array}{l}\frac{\text { Energy }}{\text { Density }} \\
\text { (Wh/Kg) }\end{array}$ & $\frac{\frac{\text { Power }}{\text { Density }}}{\underline{(\mathrm{W} / \mathrm{Kg})}}$ \\
\hline 0.35 & 0.858 & 0.756 & 10.1 & 88.1 & 0.774 & 3.68 \\
\hline 0.88 & 0.672 & 0.641 & 8.35 & 95.4 & 0.606 & 8.51 \\
\hline 1.77 & 0.462 & 0.454 & 5.77 & 98.3 & 0.338 & 13.3 \\
\hline 3.55 & 0.151 & 0.151 & 2.58 & 99.53 & 0.064 & 15.2 \\
\hline
\end{tabular}




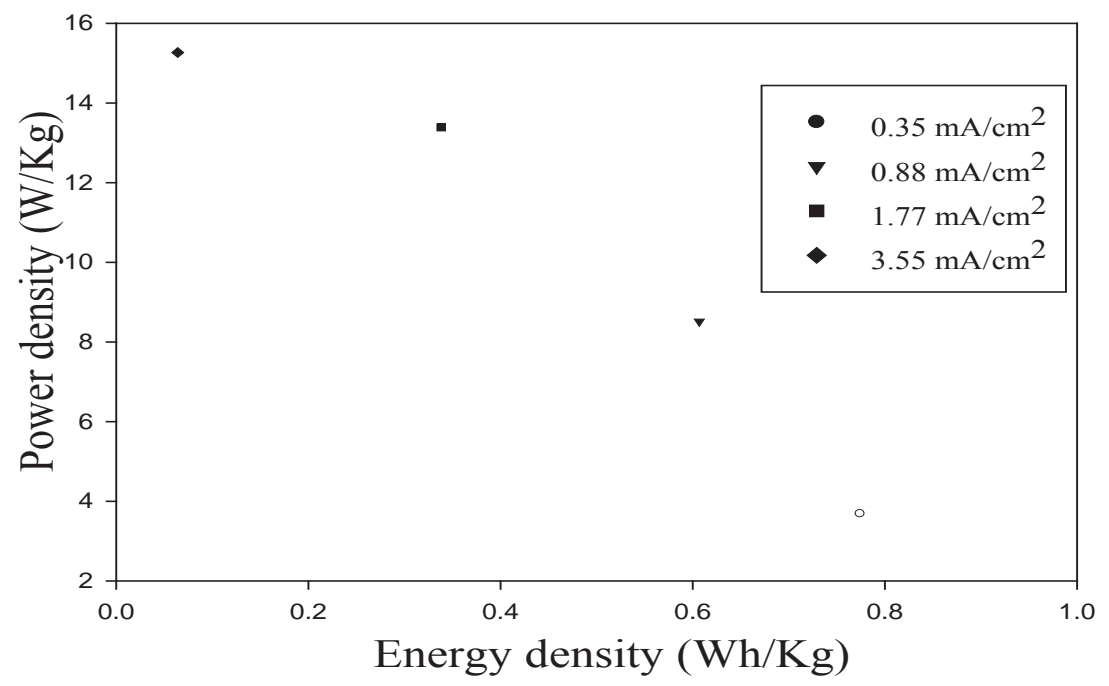

Figure 4.3. Ragone plot for the symmetric capacitor of Fig. 4.1.

\subsubsection{Impedance Spectroscopy}

Impedance spectroscopy has been carried out on two symmetric cells to analyze the frequency response of the capacitance, to understand the physical processes involved in the electrochemical reactions, and to compare our Ketjchenblack electrodes with a commercial carbon sheet electrode. Two cells were assembled for this study. The AC impedance measurements were taken using an Electrochemical Analyzer, $\mathrm{CH}-660 \mathrm{~A},{ }^{*}$ controlled by computer software. An AC signal of amplitude $5 \mathrm{mV}$ and frequencies of $10 \mathrm{KHz}$ to $1 \mathrm{mHz}$ were used for this measurement. The equivalent circuits for analysis of the AC impedance data have been fitted using Zzimpwin V3.22. $\dagger$

\footnotetext{
* CH Instruments, Inc, 3700, Tennison Hill Drive, Austin, TX.

$\dagger$ EChem. Software, Ann Arbor, MI.
} 
Figure 4.4 shows the Nyquist plot of the impedance measurements for the Ketjchenblack cell (Swagelok-type PFA cell, Celgard 3501separator, 10\% PTFE/carbon black). Table 4.3 summarizes the equivalent circuit parameters for this symmetric capacitor and Fig. 4.5 displays the frequency vs. power response.

A second symmetric cell was assembled with two commercial carbon sheet electrodes for comparison with the above Ketjchenblack cell. The equivalent circuit parameters for the two cells are compared in Table 4.3. The CV curves, constant current charge/discharge curves, and cycle life for this cell are in Appendix C. The impedance of this cell was measured over the same frequency range (10 KHz to $1 \mathrm{mHz}$ ) (see Fig C.4).

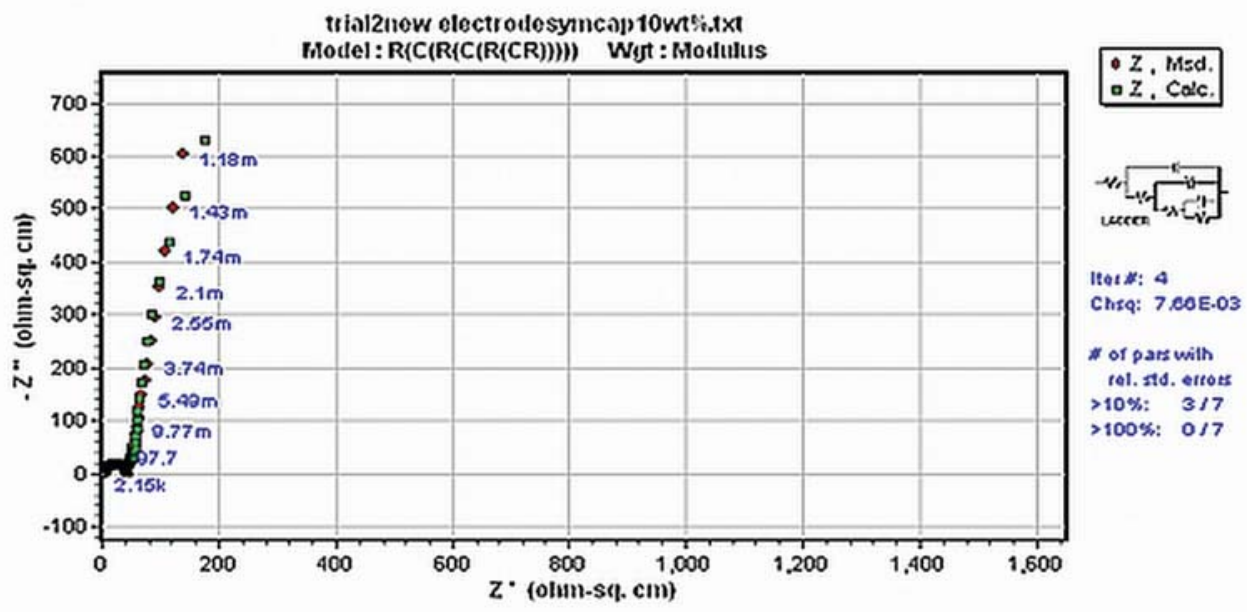

'Figure 4.4. Impedance data (red diamonds) for the symmetric capacitor (same cell as Fig. 4.1) compared to data fitted (green squares) with the ladder equivalent circuit model, Fig. 3.7. 


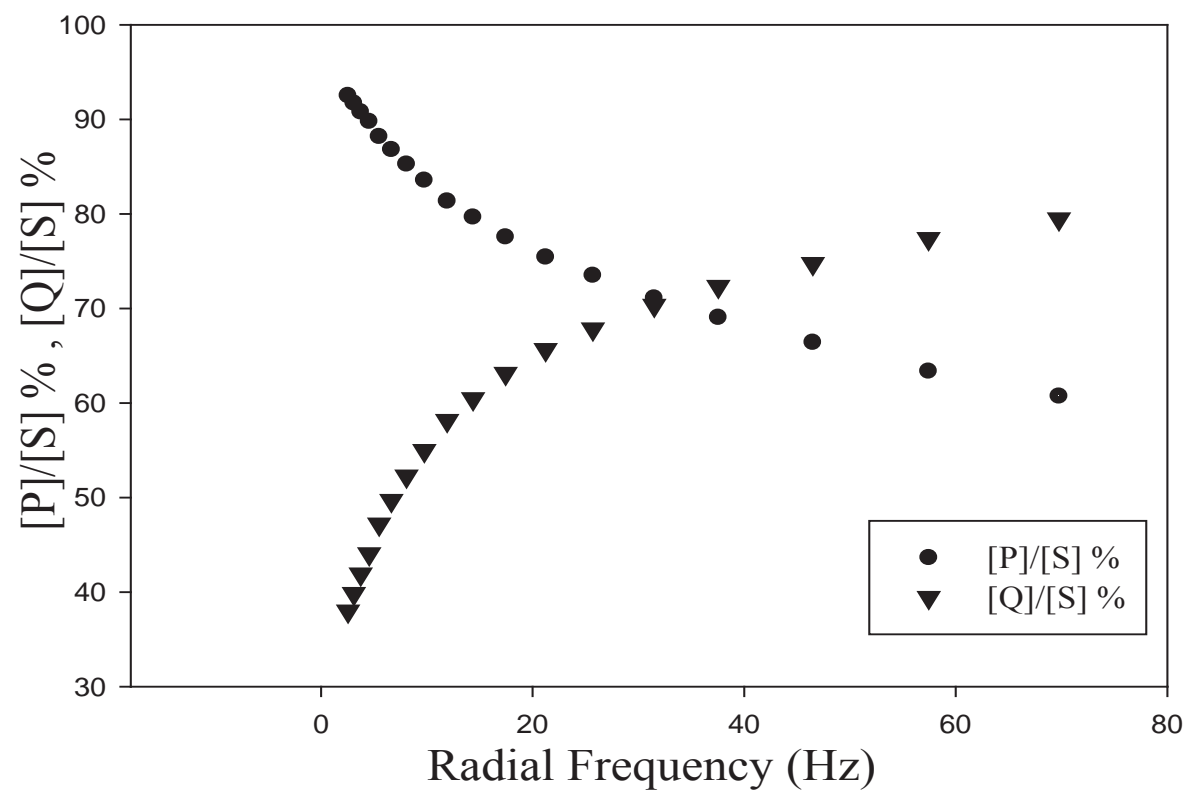

Figure 4.5. Frequency vs. complex power plot for the symmetric capacitor (same cell as Fig. 4.1).

Table 4.3

Equivalent circuit (ladder, Fig. 3.7) parameters for the symmetric capacitor

(Fig. 4.4) compared with those for a commercial carbon sheet material.

\begin{tabular}{ccc}
\hline Model Parameters & Commercial Sheet & $\underline{10 \mathrm{wt} \% \text { PTFE }}$ \\
\hline Rs & 3.425 & 3.637 \\
C1 & 1.368 & $8.598 \mathrm{E}-6$ \\
R1 & 0.3163 & 33.11 \\
C2 & 0.01637 & 0.1296 \\
R2 & 0.2672 & 69.54 \\
C3 & 3.658 & 0.1111 \\
R3 & 9.193 & 2936 \\
Chi-Squared & $2.951 \mathrm{E}-04$ & $7.662 \mathrm{E}-03$
\end{tabular}




\subsection{Electrochemical Characterization of Asymmetric Capacitor}

\subsubsection{Constant Current Experiment}

An asymmetric capacitor using a Ketjenblack electrode and a nickel electrode (see sections $3.2 \& 3.3)$ has been constructed. The constant current charge/discharge cycling (1250 cycles) experiment has been performed at four different currents densities: 0.35 $\mathrm{mAcm}{ }^{2}, 0.88 \mathrm{~mA} / \mathrm{cm}^{2}, 1.75 \mathrm{~mA} / \mathrm{cm}^{2}$ and $3.55 \mathrm{~mA} / \mathrm{cm}^{2}$. Figure 4.6 shows the potential vs. time response of the asymmetric capacitor, and Fig. 4.7 depicts the potential vs. time response of capacitance during cycle life testing. Table 4.4 summarizes the cell capacitance, power and energy density calculated at four current densities. Figure 4.8 shows a Ragone plot for this capacitor. Appendix A discusses a calculation of the optimum electrode mass ratio for this asymmetric cell.

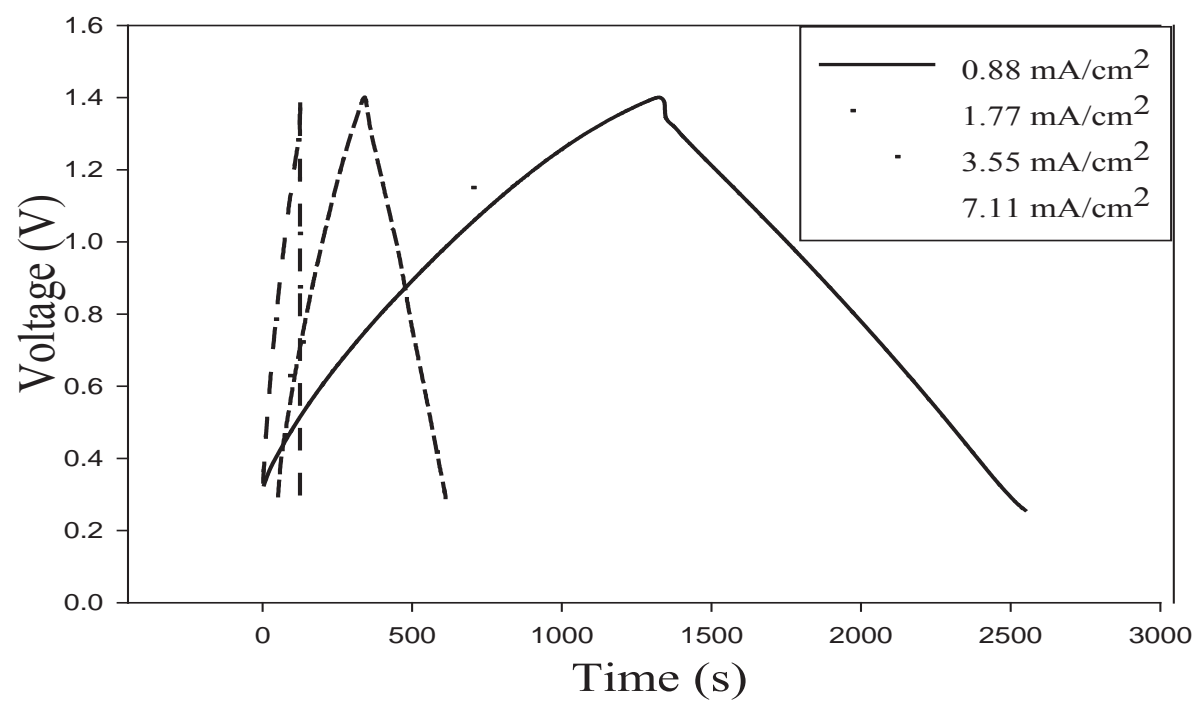

Figure 4.6. Potential vs. time response for the asymmetric (SW-77) capacitor obtained at different current densities. 


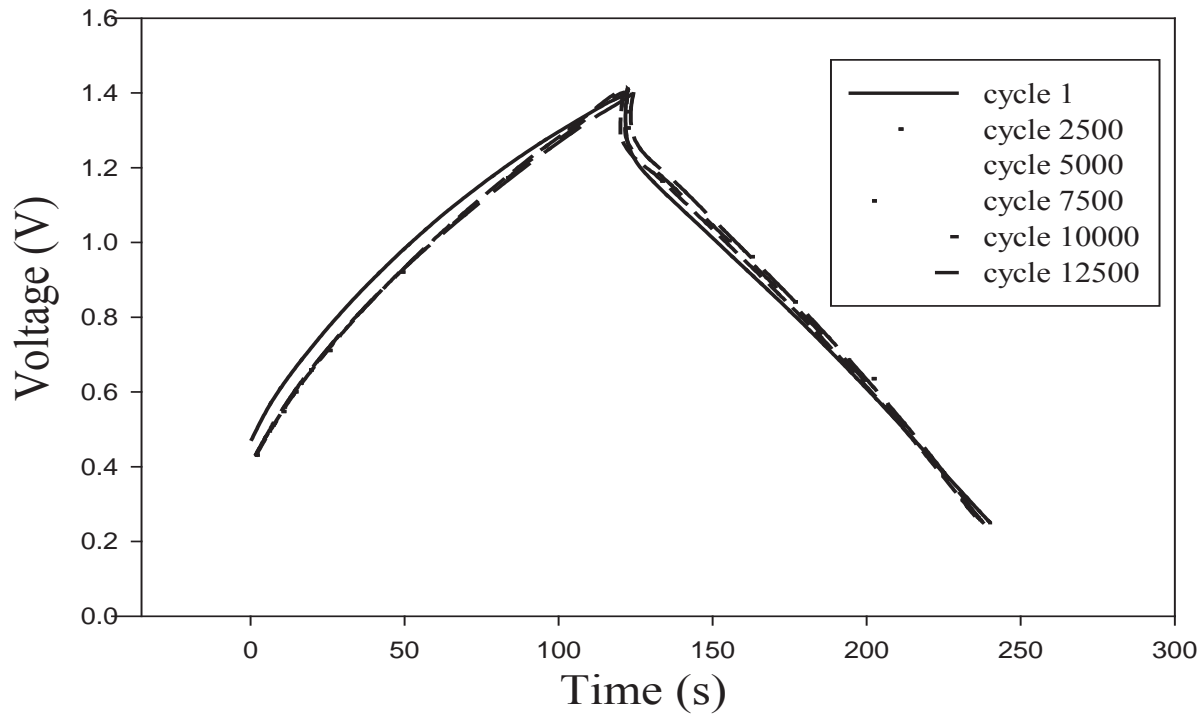

Figure 4.7. Potential vs. time response for the asymmetric capacitor at different cycle numbers, at $3.55 \mathrm{~mA} / \mathrm{cm}^{2}$ (same cell as Fig. 4.6).

Table 4.4.

Cell capacitance, power and energy densities calculated for the asymmetric capacitor at different current densities (using equations 3.7, 3.8, and 3.9 respectively).

\begin{tabular}{|c|c|c|c|c|c|c|}
\hline$\frac{\frac{\text { Current }}{\text { Density }}}{\left(\mathrm{mA} / \mathrm{cm}^{2}\right)}$ & $\frac{\frac{\text { Charge }}{\text { Capacity }}}{(\mathrm{C})}$ & $\frac{\frac{\text { Discharge }}{\text { Capacity }}}{(\mathrm{C})}$ & $\frac{\frac{\text { Cell }}{\text { Capacitance }}}{(\mathrm{F} / \mathrm{g})}$ & $\frac{\frac{\text { Columbic }}{\text { Efficiency }}}{(\%)}$ & $\begin{array}{l}\text { Energy } \\
\text { Density } \\
\text { (Wh/Kg) }\end{array}$ & $\frac{\underline{\text { Power }}}{\text { Density }} \frac{(\mathrm{W} / \mathrm{Kg})}{}$ \\
\hline 0.88 & 0.00093 & 0.00093 & 16.94 & 91.81 & 4.15 & 12.10 \\
\hline 1.77 & 0.00084 & 0.00081 & 16.34 & 96.79 & 3.92 & 24.17 \\
\hline 3.55 & 0.00077 & 0.00075 & 15.33 & 97.905 & 3.59 & 47.64 \\
\hline 7.11 & 0.00069 & 0.00069 & 13.65 & 98.86 & 3.14 & 91.67 \\
\hline
\end{tabular}




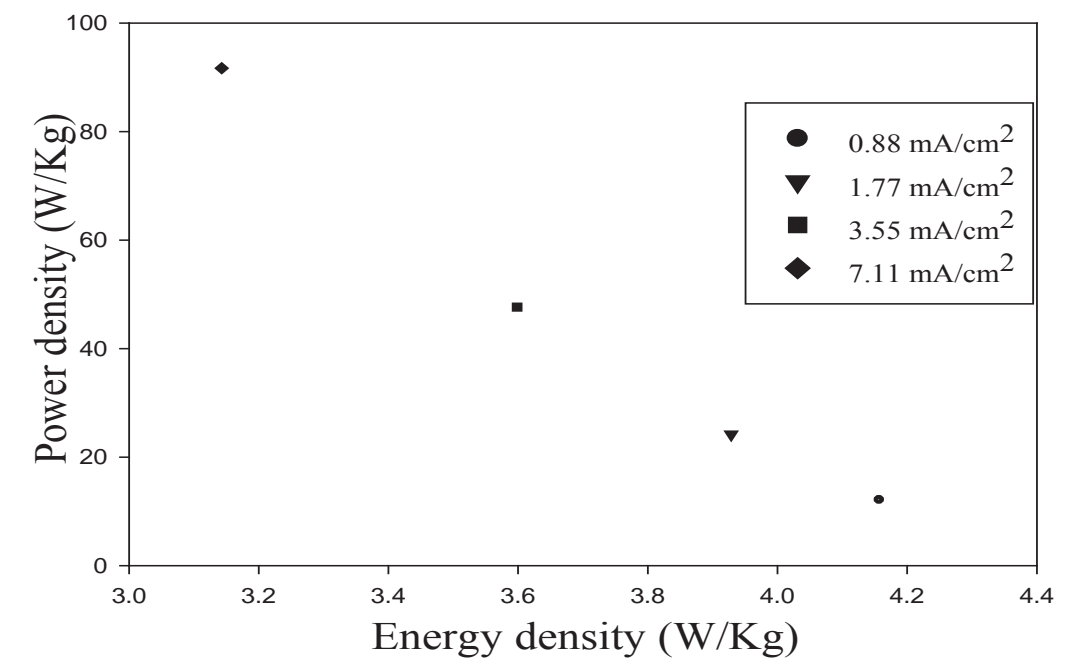

Figure 4.8. Ragone plot for the asymmetric capacitor (same cell as Fig. 4.6).

\subsubsection{Cycle Life Testing}

In order to measure the cycle life of the asymmetric capacitor, it was cycled at a constant current of $3.55 \mathrm{~mA} / \mathrm{cm}^{2}$ until the discharge capacity reduced to $80 \%$ of the initial capacity at 14,500 cycles $\left(100 \%\right.$ defined at $250^{\text {th }}$ cycle). Figure 4.9 shows the charge and discharge capacity variation during the cycling. Between cycles 1 and 250, the previous experiments were conducted (see section 4.2.1). 


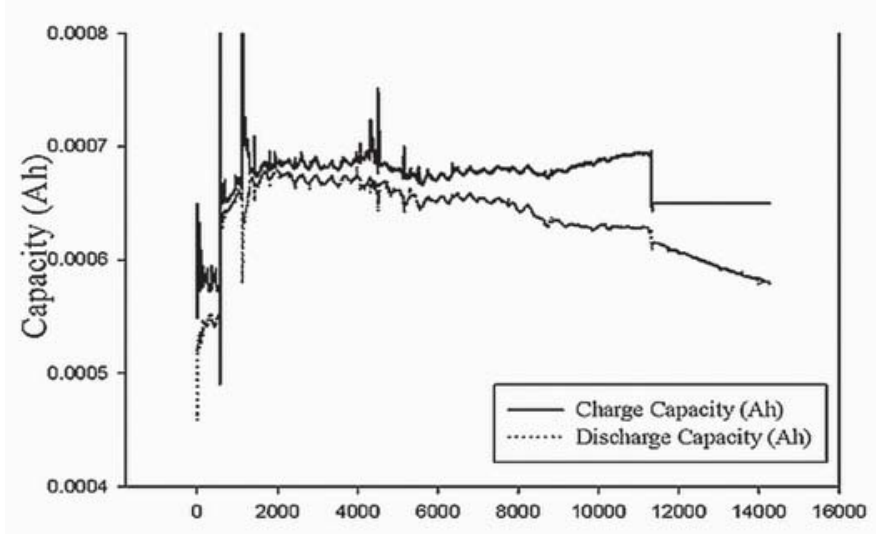

Figure 4.9. Capacity variation with cycle number for the asymmetric capacitor (SW-77).

\subsubsection{Impedance Spectroscopy and Cell Failure Analysis}

In order to find out the cause for cell failure, impedance measurements were carried out using a $5 \mathrm{mV}$ AC signal in the frequency range of $10 \mathrm{Khz}$ to $1 \mathrm{mHz}$ at the end of the $14,250^{\text {th }}$ cycle and compared with data already recorded after the $250^{\text {th }}$ cycle of the test (Fig. 4.10).

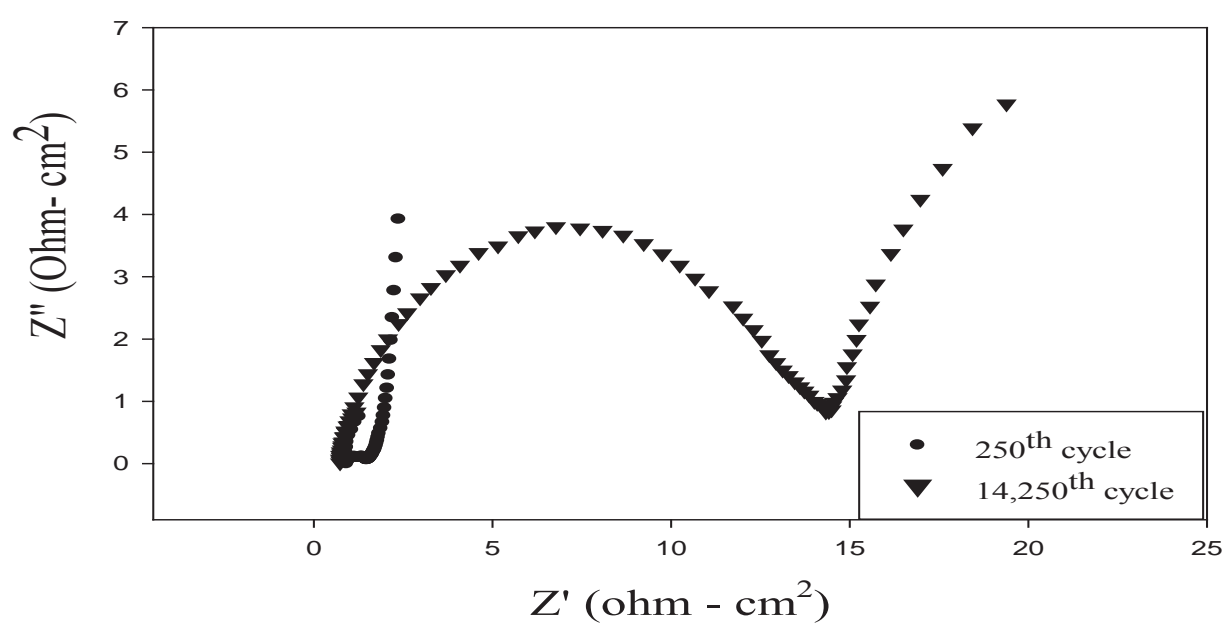

Figure 4.10. Nyquist plots obtained at $250^{\text {th }}$ and $14,250^{\text {th }}$ cycles for the asymmetric capacitor (SW-77). 


\subsubsection{Frequency Response Analysis}

From the real and imaginary impedance data the frequency response of the asymmetric capacitor was calculated (refer section 3.6.3b) and is shown in Fig. 4.11.

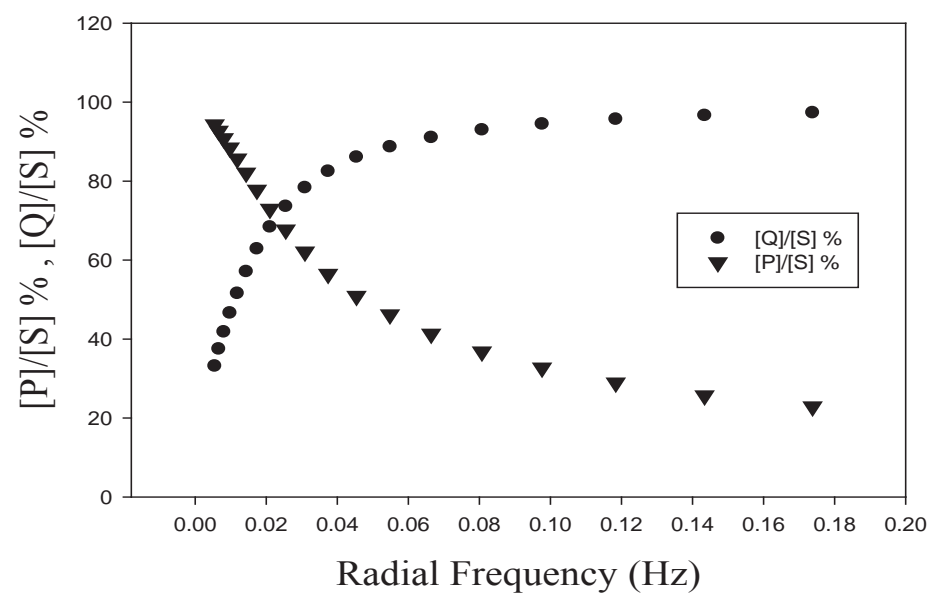

Figure 4.11. Frequency vs. complex power plot for the asymmetric capacitor.

\subsubsection{Self-Discharge Analysis}

Self-discharge measurement was carried out at the end of the $200^{\text {th }}$ cycle of the cycling test. The cell was charged to $1.4 \mathrm{~V}$ and then the circuit left open. The open circuit potential was followed with time (Fig. 4.12).

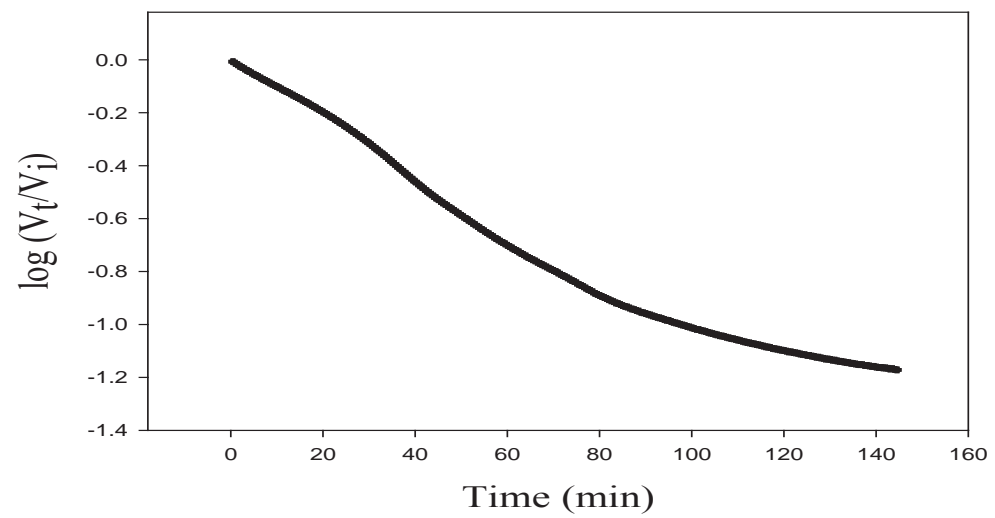

Figure 4.12. Open circuit potential $v s$. time response of the asymmetric capacitor (SW-77). 


\section{DISCUSSION}

\subsection{Evaluation of Symmetric Capacitor}

Cyclic voltammograms (CVs) of the symmetric capacitor are displayed in Fig.4.1. The fact that the CVs are asymmetric (i.e., not rectangular) about the zero current axis clearly indicates that the capacitor does not behave like an ideal parallel plate capacitor. Two redox peaks are seen at $0.75 \mathrm{~V}$ (charge) and $-0.5 \mathrm{~V}$ (discharge), and are more evident at high scan rates. These are believed to be caused by faradaic reactions, which are responsible for the pseudo-capacitance. Hence, both double-layer and pseudo-capacitance contribute to the overall capacitance for these carbon sheet electrodes. These redox peaks could be attributed to surface functional groups on the carbon electrodes or adsorption of ions on the carbon surface. ${ }^{44}$ The cell capacitance is calculated at different scan rates and reported in table 4.1. The cell capacitance decreases with increasing scan rate. This is believed to be caused by an increase in IR-drop which arises from the complex internal

distribution of resistances within porous electrodes. ${ }^{44}$ It was also suggested that at high scan rates the ions may not penetrate as deeply into the pores and do not completely access all the surface area, thus limiting the capacitance.

The following observation has been noted during the constant current experiment. The potential vs. time plot (see Fig. 4.2) shows that the charge and discharge behavior is not linear as would be expected for an ideal parallel plate capacitor. This agrees with porous electrode capacitance behavior. ${ }^{11}$ The cell capacitance and the energy density decrease as we increase the current density due to greater IR losses at higher currents (Table 4.2). However, the columbic efficiency is increased as we increase the current 
density although it was constant in the CV experiment (Table 4.1). The Ragone plot (Fig. 4.3 and Table 4.2) shows that the maximum energy density is obtained at the lowest power density (and the lowest current), as is normally seen.

The Nyquist plot ( Z'vs Z”) for the symmetric capacitor (see Fig. 4.4) displays a semi-circle at high frequency followed by a straight line at low frequency. The semi-circle is the typical behavior of charge transfer resistance combined with double-layer capacitance, and the straight line depicts pure capacitance character. In order to understand the physical processes occurring at the electrode/electrolyte interface, the impedance data are fitted to an equivalent circuit model. The ladder model electrical circuit (Fig. 3.7) includes series and parallel combinations of resistance and capacitance and has been found to represent the porous nature of carbon electrodes. ${ }^{42}$ The model parameters have been extracted and compared in Table 4.3 with those for an electrode prepared using a carbon sheet electrode produced commercially. It is observed that the internal resistances $\left(\mathrm{R}_{1}\right.$ to $\mathrm{R}_{3}$ ) of this material increase as we move down into the circuit. These results are consistent with the porous nature of the electrodes; the pores deep inside were not accessible to the ions due to the higher percentage of smaller pores. This is seen to be greatly exaggerated for the Ketjenblack electrode material $\left(\mathrm{R}_{3}>\mathrm{R}_{2}>\mathrm{R}_{1}\right)$.

The time constant is the most important parameter as a figure of merit of the electrochemical capacitor assembly. The time constant defines the amount of time required to completely charge the capacitor. ${ }^{42}$

The frequency response of the capacitor has been obtained from the plot of complex power $v s$. frequency (see Fig. 4.11). The real and imaginary powers vary with frequency in opposite directions as expected, and intersect at a particular frequency. The crossing occurs 
at frequency $\mathrm{f}_{0}$, known as the resonance or characteristic frequency of the capacitor, from which the relaxation time constant, $\tau_{0}\left(=1 / 2 \pi \mathrm{f}_{0}\right)$, can be determined. This time constant, $\tau_{0}$, defines the transition of the electrochemical capacitor from purely resistive to purely capacitive behavior. For a high frequency, $\mathrm{f}>1 / \tau_{0}$, the capacitor acts as a pure resistor, and for $\mathrm{f}<1 / \tau_{0}$, it behaves as a pure capacitor. The time constant of $4 \mathrm{~ms}$ was obtained for the symmetric capacitor. The literature values for commercially available carbon symmetric capacitors vary between $0.08 \mathrm{~s}$ and $3.1 \mathrm{~s}^{43}$

\subsection{Evaluation of Asymmetric Capacitor}

The charge and discharge behavior of the asymmetric capacitor is examined by the constant current cycle measurement. Figure 4.6 showed the potential vs. time response of the asymmetric capacitor at different current densities. The cell capacitance does not vary much as the current density increased and the capacitance was increased at least three times more than the symmetric capacitor at the respective discharge current. The Ragone plot (see Fig. 4.8) demonstrates the energy and power density of asymmetric capacitor. The energy density increased from $0.34 \mathrm{Wh} / \mathrm{Kg}$ to $3.98 \mathrm{Wh} / \mathrm{Kg}$. The huge increase in energy density as compared to the symmetric capacitor is due to the faradaic electrode in the cell which is nickel oxyhydroxide electrode in this case.

In order to study the cycle life of this capacitor, the cell was cycled using $0.88 \mathrm{~mA}$ $/ \mathrm{cm}^{2}$ until the capacity dropped to $80 \%$ of the initial capacity. Fig. 4.7 shows the potential $v s$. time response of the capacitor between the $1^{\text {st }}$ cycle and the $12,500^{\text {th }}$ cycle. These plots overlay well and show the superior reproducibility of charge and discharge behavior. The charge and discharge capacities are calculated and plotted (see Fig. 4.9). The columbic 
efficiency was maintained above $95 \%$ for the first 8,000 cycles. The discharge capacity started to decrease from the $8,000^{\text {th }}$ cycle and continued until the $11,500^{\text {th }}$ cycle. After the $11,500^{\text {th }}$ cycle the capacity started to decline rapidly and approached the cut-off discharge capacity $(80 \%)$ at the $14,500^{\text {th }}$ cycle.

To define the cell failure mechanism, impedance spectroscopy was performed at the end of the $12,500^{\text {th }}$ cycle in the asymmetric capacitor and compared with the data already recorded at the $250^{\text {th }}$ cycle. Figure 4.10 compares the impedance plots between the $250^{\text {th }}$ cycle and the $14,250^{\text {th }}$ cycle. The charge transfer resistance (i.e., the intersection of semicircle on the real impedance axis ${ }^{42}$ ) is hugely increased (from $1.8 \mathrm{ohm} / \mathrm{cm}^{2}$ to 14.8 $\mathrm{ohm} / \mathrm{cm}^{2}$ ) between these cycles. The exact cause for this increase in impedance is not known conclusively. We believe that the combination of electrolyte starvation, which has been noted during the disassembling of the cell at the end of cycle life testing, and the increase in the charge transfer resistance of the faradaic electrode are causing the cell failure.

The frequency response of the asymmetric capacitor has been calculated from the impedance data. Figure 4.11 shows the complex power $v s$. frequency. From the intersection of these plots the relaxation time constant was found to be $6.28 \mathrm{~s}$ for the asymmetric capacitor. The relaxation times for asymmetric cells are typically longer than for symmetric cells. The literature values for commercially available carbon asymmetric capacitors vary between $0.14 \mathrm{~s}$ and $7.5 \mathrm{~s} .^{43}$ 


\subsection{Self-discharge Analysis}

Self-discharge is an important shortcoming of any electrochemical energy storage device. The practical significance of this self-discharge process depends upon the application of these devices. Self-discharge may not be of practical import if the device is recharged frequently, e.g., for start/stop applications in hybrid electric vehicles. On the other, self-discharge is of major importance for devices used in standby applications where the charged battery stands for appreciable periods of time before recharge, e.g., bridging short-term power outages or load-leveling.

It is known that the charged electrochemical devices are in a state of high Gibbs energy compared to that of the discharged states; therefore there is a thermodynamic driving force for their self-discharge on open-circuit. The actual rate of decline of the potential during self-discharge depends upon the mechanism. This mechanism can be identified by measuring the open circuit potential of the device with time. Niu, et al., derived the potential $v s$. time relation for three different mechanism. ${ }^{44}$ When self-discharge is caused by a non-diffusion-controlled faradaic process associated with reduction or oxidation of either the products from overcharge or redox-reaction impurities such as $\mathrm{Fe}^{2+} / \mathrm{Fe}^{3+}$ or solution oxygen, the decline of voltage, $\mathrm{V}$, versus log $\mathrm{t}$ would give a straight line according to the kinetic equation (5.1) for this process, where $\theta$ is an integration constant arising in the mathematics. If the self-discharge is caused by impurities at a planar electrode, the potential would decline with the square-root of $t$, to satisfy the semi-infinite, diffusion-controlled faradaic process according to equation 5.2. If self-discharge is due to short-circuit leakage between one electrode and another, e.g., in a faulty bipolar cell, $\ln V_{\mathrm{t}}$ versus t would follow a linear relationship, where $R$ is an ohmic load resistance (eqn. 5.3). 


$$
\begin{gathered}
\mathrm{Vt}=\mathrm{Vi}-\mathrm{A} \log (\mathrm{t}+\theta) \\
\mathrm{V}_{\mathrm{t}}=\mathrm{V}_{\mathrm{i}}-\frac{2 \mathrm{zFAD}{ }^{\frac{1}{2}} \pi^{1 / 2} \mathrm{C}_{0} \mathrm{t}^{1 / 2}}{\mathrm{C}} \\
\ln \mathrm{V}_{\mathrm{t}}=\ln \mathrm{V}_{\mathrm{i}}-\frac{\mathrm{t}}{\mathrm{RC}}
\end{gathered}
$$

In this study, the asymmetric capacitor has been charged to $1.4 \mathrm{~V}$ at $0.88 \mathrm{~mA} / \mathrm{cm}^{2}$ after the end of the $200^{\text {th }}$ cycle. The current was stopped at that voltage, and the OCV, measured for several minutes $(\mathrm{t})$. The decline of potential during self-discharge is examined by plotting $\mathrm{V} v s . \log \mathrm{t}, \mathrm{V}_{\mathrm{t}}$ as a function of $\mathrm{t}^{1 / 2}$, or $\log \left(\mathrm{V}_{\mathrm{i}} / \mathrm{V}_{\mathrm{t}}\right) v s$. $\mathrm{t}$. The predicted linear relationship is obtained only for eqn. 5.3, $\log \left(\mathrm{V}_{\mathrm{i}} / \mathrm{V}_{\mathrm{t}}\right) v s . \mathrm{t}$, and the result is shown in Fig. 4.12. This observed behavior suggests that the self-discharge is caused by an internal ohmic leakage pathway between the two electrodes. Excessive carbon electrode swelling in the concentrated $\mathrm{KOH}$ solution is observed which could have caused the internal short circuit. 


\section{CONCLUSIONS AND FUTURE WORK}

\subsection{Conclusions}

This study has successfully demonstrated the utilization of a novel carbon foam supported, nickel hydroxide, positive electrode in an asymmetric EC capacitor. Complete electrochemical characterization of these electrodes has been performed to determine the suitability of commercializing this technology with these two high-rate, light weight electrodes.

To understand the capacitance properties of as-synthesized carbon sheet electrodes, a symmetric capacitor is constructed and its performance is extensively characterized electrochemically. Cyclic voltammetry confirmed that the overall capacitance is the combination of double-layer capacitance and pseudo-capacitance, possibly due to functional groups on the carbon surface. The maximum specific capacitance, power density, and energy density are obtained from constant current cycle tests as 10.1 F/g, 3.68 $\mathrm{W} / \mathrm{Kg}$ and $0.774 \mathrm{Wh} / \mathrm{Kg}$, respectively. Impedance studies and the equivalent circuit model for the capacitor showed that the material has a complex porous network structure and the deep pores were not accessible to the ions, hence they could not contribute to the capacitance. The resonance frequency of the capacitor is found to be $4 \mathrm{~ms}$.

An asymmetric capacitor consisting of a light weight, carbon foam supported nickel electrode has been successfully assembled showing stable performance over a wide range of current densities with good energy and power density characteristics. The cycle tests indicate superior reproducibility of capacitance behavior over 14,500 cycles $(>80 \%)$, with high efficiency ( $>96 \%)$. The maximum specific capacitance, power and energy 
densities obtained are $16.9 \mathrm{~F} / \mathrm{g}, 12.1 \mathrm{~W} / \mathrm{Kg}$ and $4.15 \mathrm{Wh} / \mathrm{Kg}$, respectively. Impedance spectroscopy confirms that the charge transfer resistance in the faradaic electrode increased significantly during cycling. This increase may have contributed to an increase in impedance in the cell which ultimately led cell failure. The frequency response studies show the asymmetric capacitor has a resonance frequency of $6.3 \mathrm{~s}$.

The self-discharge characteristics of the asymmetric capacitor are analyzed, and a mechanism causing the self-discharge is proposed. It has been found that the capacitor suffers internal ohmic leakage between the two electrodes.

\subsection{Future Work}

Although we have successfully showcased the stable performance of an asymmetric capacitor and reached a few important conclusions about cell failure and the self-discharge of the asymmetric capacitor there is ample scope for further investigation.

In order to optimize the performance of an asymmetric cell, the faradaic electrode component should be matched with the capacitive electrode. The capacity ratio (and mass ratio, $\mathrm{m}_{\text {pos }} / \mathrm{m}_{\text {neg }}$ ) of these electrodes is critically important to assure that the cell is limited by the capacitive electrode to avoid overcharge and over discharge of the faradaic electrode. Hence it is mandatory to optimize this mass ratio to give better performance such as higher energy density and longer cycle life. A maximum mass ratio, $\mathrm{m}_{\mathrm{Neg}} / \mathrm{m}_{\mathrm{Pos}}$, of 4.7 has been calculated for this electrode pair in Appendix A. The optimum ratio is expected to be less than this number. Future work is necessary to determine this optimum experimentally. 
Electrode swelling should be addressed to prevent the short circuit in order to reduce the self-discharge of the cell. This might be done by adding various additives into the carbon electrodes.

Even though the carbon electrode has a huge surface area, most of the area has not been utilized due to pore size limitation. Future research should be directed to alter the pore size distribution and to engineer an electrode with a pre-determined or controlled pore size to improve the capacitance utilization. Surface properties of the carbon materials using SEM, TEM and Raman spectroscopic techniques should be studied. 


\section{REFERENCES}

1. Conway, B. E., Electrochemical Supercapacitors: Scientific Fundamentals and Technological Applications. 1 ed.; Kluwer Academic Publishers: Norwell, MA, 1999.

2. Park, J. H.; Park, O. O.; Shin, K. H.; Jin, C. S.; Kim, J. H., An Electrochemical Capacitor Based on a $\mathrm{Ni}(\mathrm{OH})_{2} /$ Activated Carbon Composite Electrode. Electrochemical and Solid-state Letters 2002, 5, H7.

3. Lang, J. W.; Kong, L. B.; Liu, M.; Luo, Y. C.; Kang, L., Asymmetric supercapacitors based on stabilized $\alpha-\mathrm{Ni}(\mathrm{OH})_{2}$ and activated carbon. Journal of Solid State Electrochemistry 2010, 14 (8), 1533-1539.

4. Bhatia, A. S. Nickel Hydroxide Impregnated Carbon Foam Electrodes for Rechargeable Nickel Batteries. M.S. Thesis, Michigan Technological University, Houghton, 2003.

5. Chye, M. B. Development and Characterization of a Rechargeable Carbon Foam Electrode Containing Nickel Oxyhydroxide Active mass. PhD. Thesis, Michigan Technological University, Houghton, 2011.

6. Chiang, Y.-M., Electrochemical Energy Storage for Transportation and the Power Grid. Dept. of Materials Science and Engineering. American Physical Society Webstie, http://www.aps.org/units/gera/meetings/march10/upload/Chiang_APS_March2010_final_f or_posting.pdf (Accessed March, 2011).

7. H.I. Becker, Low voltage electrolytic capacitor, U.S. Patent No. 2800 616, (1957).

8. Boos, D. I, Electrolytic Capacitor having Carbon Paste Electrodes, U.S. Patent 3536 963, (1970).

9. Trasatti, S.; Buzzanca, G., Ruthenium dioxide: a new interesting electrode material. Solid state structure and electrochemical behaviour. Journal of Electroanalytical Chemistry 1971, 29 (2), A1-A5.

10. Linden, D. In Handbook of batteries, Elsevier: 1995; Chapter 4, pp. 265.

11. Conway, B. E.; Pell, W.; Liu, T.-C., Diagnostic analyses for mechanisms of selfdischarge of electrochemical capacitors and batteries. Journal of Power Sources 1997, 65, 53-56.

12. Kötz, R.; M. Carlen., Principles and applications of electrochemical capacitors. Electrochimica Acta 1999, 45, 2483-2498.

13. Helmholtz, H., Theory of Electrical Double Layer. Wied. Ann. 1879, 7, 337. 
14. Gouy, G., Constitution of the electric charge at the surface of an electrolyte. J. phys 1910, 9 (4), 457-467.

15. Stern, O., The theory of the electric double layer. $z$. Electrochem 1924, 30, 508.

16. Pell , W. G.; Conway, B. E., Double-layer and pseudo-capacitance types of electrochemical capacitors and their applications to the development of hybrid devices. Journal of Solid State Electrochemistry 2003.

17. Conway, B.; Birss, V.; Wojtowicz, J., The role and utilization of pseudo-capacitance for energy storage by supercapacitors. Journal of Power Sources 1997, 66 (1-2), 1-14.

18. Halper, M.; Ellenbogen, J., Supercapacitors: A brief overview. 2006. Mitre Website. http://www.mitre.org/work/tech_papers/tech_papers_06/06_0667/06_0667.pdf (Accessed March, 2011).

19. Frackowiak, E.; Beguin, F., Carbon materials for the electrochemical storage of energy in capacitors. Carbon 2001, 39 (6), 937-950.

20. Shi, H., Activated carbons and double layer capacitance. Electrochimica Acta 1996, 41 (10), 1633-1639.

21. Beguin, F.; Frackowiak, E., Carbons for Electrochemical Energy Storage and Conversion Systems 1 ed.; CRC Press: 2009.

22. Mayer, S.; Pekala, R.; Kaschmitter, J., The Aerocapacitor: An Electrochemical Double Layer Energy Storage Device. Journal of the Electrochemical Society 1993, 140, 446.

23. Pekala, R.; Farmer, J.; Alviso, C.; Tran, T.; Mayer, S.; Miller, J.; Dunn, B., Carbon aerogels for electrochemical applications. Journal of Non-Crystalline Solids 1998, 225 (1), $74-80$.

24. Saliger, R.; Fischer, U.; Herta, C.; Fricke, J., High surface area carbon aerogels for supercapacitors. Journal of Non-Crystalline Solids 1998, 225 (1), 81-85.

25. Niu, C.; Sichel, E.; Hoch, R.; Moy, D.; Tennent, H., High power electrochemical capacitors based on carbon nanotube electrodes. Applied Physics Letters 1997, 70, 1480.

26. Amatucci, G.; Badway, F.; Du Pasquier, A.; Zheng, T., An asymmetric hybrid nonaqueous energy storage cell. Journal of the Electrochemical Society., 2001, 148, A930.

27. Zheng, J.; Jow, T., High energy and high power density electrochemical capacitors. Journal of Power Sources 1996, 62 (2), 155-159.

28. Chang, J.; Lin, C.; Tsai, W., Manganese oxide/carbon composite electrodes for electrochemical capacitors. Electrochemistry Communications 2004, 6 (7), 666-671. 
29. Pang, S.; Anderson, M.; Chapman, T., Novel electrode materials for thin-film ultracapacitors: comparison of electrochemical properties of sol-gel-derived and electrodeposited manganese dioxide. J.Electrochem.Soc., 2000, 147 (2), 444-450.

30. Srinivasan, V.; Weidner, J., Studies on the capacitance of nickel oxide films: effect of heating temperature and electrolyte concentration. J.Electrochem.Soc., 2000, 147 (3), 880885.

31. Lin, C.; Ritter, J., Popov, BN, Characterization of Sol-Gel-Derived Cobalt Oxide Xerogels as Electrochemical Capacitors. J. Electrochem.Soc., 1998, 145, 4097.

32. Nalwa, H., Handbook of Advanced Electronic and Photonic Materials and Devices: Conducting polymers. Elsevier: 2001.

33. Mastragostino, M.; Arbizzani, C.; Soavi, F., Polymer-based supercapacitors. Journal of Power Sources 2001, 97, 812-815.

34. Fusalba, F.; Gouérec, P.; Villers, D.; Bélanger, D., Electrochemical characterization of polyaniline in nonaqueous electrolyte and its evaluation as electrode material for electrochemical supercapacitors. J. Electrochem.Soc., 2001, 148, A1.

35. Simon, P.; Gogotsi, Y., Materials for electrochemical capacitors. Nature Materials 2008, 7 (11), 845-854.

36. Beliakov, A. In Asymmetric type electrochemical capacitors, Proceedings of the International Symposium, R. Brodd; D.H. Doughty; J.H. Kim, M. M.; N. Naoi; G. Nagasubramanian; Nanjundiah, C., Eds. The Electrochemical Society,: 2002; p 7.

37. Zheng, J., The limitations of energy density of battery/double-layer capacitor asymmetric cells. J. Electrochem.Soc., 2003, 150, A484.

38. Wang, Y.; Xia, Y., Electrochemical Capacitance Performance of Hybrid Supercapacitors Based on $\mathrm{Ni}(\mathrm{OH}) /$ Carbon Nanotube Composites and Activated Carbon. J. Electrochem.Soc., 2006, 153, A743.

39. Du Pasquier, A.; Plitz, I.; Menocal, S.; Amatucci, G., A comparative study of Li-ion battery, supercapacitor and nonaqueous asymmetric hybrid devices for automotive applications. Journal of Power Sources 2003, 115 (1), 171-178.

40. Bard, A.; Faulkner, L., Electrochemical methods. Wiley New York: 1980; Vol. 316.

41. Johnson, A.; Newman, J., Desalting by means of porous carbon electrodes. $J$. Electrochem.Soc., 1971, 118, 510.

42. De Levie, R., on porous electrodes in electrolyte solutions: I. Capacitance effects. Electrochimica Acta 1963, 8 (10), 751-780. 
43. Taberna, P.; Simon, P.; Fauvarque, J., Electrochemical characteristics and impedance spectroscopy studies of carbon-carbon supercapacitors. Journal of the Electrochemical Society 2003, 150, A292.

44. Niu, J.; Pell, W.; Conway, B., Requirements for performance characterization of C double-layer supercapacitors: Applications to a high specific-area C-cloth material. Journal of Power Sources 2006, 156 (2), 725-740. 


\section{APPENDIX A}

\section{Capacity Balance Calculation for an Asymmetric Capacitor using Nickel Hydroxide and Carbon Electrodes}

Data

Theoretical capacity of defective $(x=0.25) \alpha-\mathrm{Ni}(\mathrm{OH})_{2}$

Specific capacitance of commercial carbon sheet

Mass of a single carbon sheet

Area of circular POCOfoam electrode

Density of $\mathrm{Ni}(\mathrm{OH})_{2}$

Swing voltage

$\begin{array}{rl}0.253 & \mathrm{Ah} / \mathrm{g} \\ 140.3 & \mathrm{~F} / \mathrm{g} \\ 0.1219 & \mathrm{~g} \\ 2.822 & \mathrm{~cm}^{2} \\ 2.50 & \mathrm{~g} / \mathrm{cm}^{3} \\ 1.40 & \mathrm{~V}\end{array}$

Charge on positive electrode, $\mathrm{Ni}(\mathrm{OH})_{2}, \quad \mathrm{C}_{\mathrm{Pos}}=\quad 918$

$=$ theoretical capacity $(\mathrm{C} / \mathrm{g}) *$ mass of pos electrode $(\mathrm{g}) \quad \mathrm{C} / \mathrm{g} * \mathrm{~m}_{+}$

Charge on the negative electrode, $\quad \mathrm{C}_{\mathrm{Neg}}=$

$=$ sp. capacitance $(\mathrm{F} / \mathrm{g})^{*}$ mass of neg electrode $(\mathrm{g}) *$ swing voltage $(\mathrm{V}) \quad \mathrm{C} / \mathrm{g}^{*} \mathrm{~m}$ -

Solving for the optimum

mass ratio, $\mathrm{m}_{\mathrm{Neg}} / \mathrm{m}_{\text {Pos }}$

$$
\text { (or, } \left.\mathrm{m}_{\mathrm{Pos}} / \mathrm{m}_{\mathrm{Neg}}=0.214\right)
$$

This gives the mass of $\mathrm{Ni}(\mathrm{OH})_{2}$ needed to equalize the charges of a single carbon sheet, as $\mathrm{m}_{\mathrm{Pos}}=0.214 * \mathrm{~m}_{\mathrm{Neg}}=0.026 \mathrm{~g}$

And the thickness of this active mass $(\mathrm{cm})=$

$$
\text { mass } /(\text { density } * \text { area })=0.0037 \mathrm{~cm}
$$


Calculation of time needed to obtain this thickness at $50 \mathrm{~mA}$ deposition current:

$\begin{array}{ll}\text { Thickness }= & (\mathrm{M} * \mathrm{I} * \mathrm{t}) /(\mathrm{n} * \mathrm{~F} * \mathrm{~d} * \mathrm{~A}) \\ \mathrm{M}=104.65 \mathrm{~g} / \text { mole }= & \begin{array}{l}\text { molar mass of the deposited material }(\mathrm{g}) \\ \text { current for deposition }(\mathrm{A})\end{array} \\ \mathrm{I}=50 \mathrm{~mA} & \begin{array}{l}\text { time, } \mathrm{t}(\mathrm{s}) \\ \mathrm{t}_{\text {deposition }}=\end{array} \\ \mathrm{n}=2 & \begin{array}{l}\text { Fo. of electrons involved } \\ \mathrm{F}=\end{array} \\ \mathrm{d}=2.5 \mathrm{~g} / \mathrm{cc} & \text { density of material }\left(\mathrm{g} / \mathrm{cm}^{3}\right) \\ \mathrm{A}=2.822 \mathrm{~cm}^{2} & \text { electrode } \quad \text { area }\end{array}$

Time calculated $(\mathrm{s}) \quad=\quad 962 \mathrm{~s}$ 


\section{APPENDIX B}

\section{Secondary Discharge Plateau, CV Studies}

A study of the secondary discharge plateau was conducted to measure the precise charge and discharge capacities over a large number of $\mathrm{CV}$ cycles, measuring these capacities using a gold supported nickel electrode. Similar studies were conducted previously by V. Srinivasin, J. Weidner, and B. Cornilsen for a more limited number of cycles. Srinivasan, et al., demonstrated a dependence on an oxygen or nitrogen purge.

Nickel hydroxide was deposited cathodically onto a spherical gold electrode (1.89 mm diameter) using an Arbin potentiostat (model no. BT2000). The spherical gold electrode was borrowed from Dr. Haying Liu. The deposition was carried out at room temperature. A $1.8 \mathrm{M} \mathrm{Ni}\left(\mathrm{NO}_{3}\right)_{2}$ deposition solution was prepared using a solvent mixture of 50 volume percent (v/o) ethanol and $50 \mathrm{v} / \mathrm{o}$ water. A cathodic current density of 5 $\mathrm{mA} / \mathrm{cm}^{2}$ and a deposition time of $30 \mathrm{~min}$. were employed. The CV experiments were performed at a rate of $2 \mathrm{mV} / \mathrm{s}$ in 3 wt. $\% \mathrm{KOH}$, and a $\mathrm{Hg} / \mathrm{HgO}$ reference electrode was used.

Figure B.1 shows a CV for a nickel electrode cycled between $-400 \mathrm{mV}$ and 600 $\mathrm{mV}$ which exhibits a secondary discharge plateau. When the potential window was reduced to 0 to $600 \mathrm{mV}$, no secondary discharge plateau is observed (see Figure B.2). Charge and discharge capacities were calculated using an Excel program developed by Terry Mazure. Figure B.3 shows the capacity variation of the nickel electrode when the potential window is varied. For cycles 1 to 16 a potential window of $-400 \mathrm{mV}$ to $600 \mathrm{mV}$ was used to see the second discharge plateau. For cycles 17 to 25 a potential window of 0 
to $600 \mathrm{mV}$ was used, and for cycles 26 to 41 the potential window of $-400 \mathrm{mV}$ to $600 \mathrm{mV}$ was again employed. Fig. B.4 represents the charge and the primary discharge capacity variation of nickel electrode without any secondary discharge plateau. In order to see if the secondary discharge plateau is due to oxygen, a new nickel electrode was deposited using the same conditions and the cell was purged with $\mathrm{N}_{2}$ gas. No plateau was observed in the negative potential region and Fig.B.5 shows the charge and primary discharge capacity variation during various cycles. At the end of $132^{\text {nd }}$ cycle, $\mathrm{O}_{2}$ gas was purged into the cell, and the secondary discharge plateau appeared in the negative potential region $(-200 \mathrm{mV})$. Fig.B.6 shows the capacity variation of charge and primary and secondary discharge plateau during various cycles.

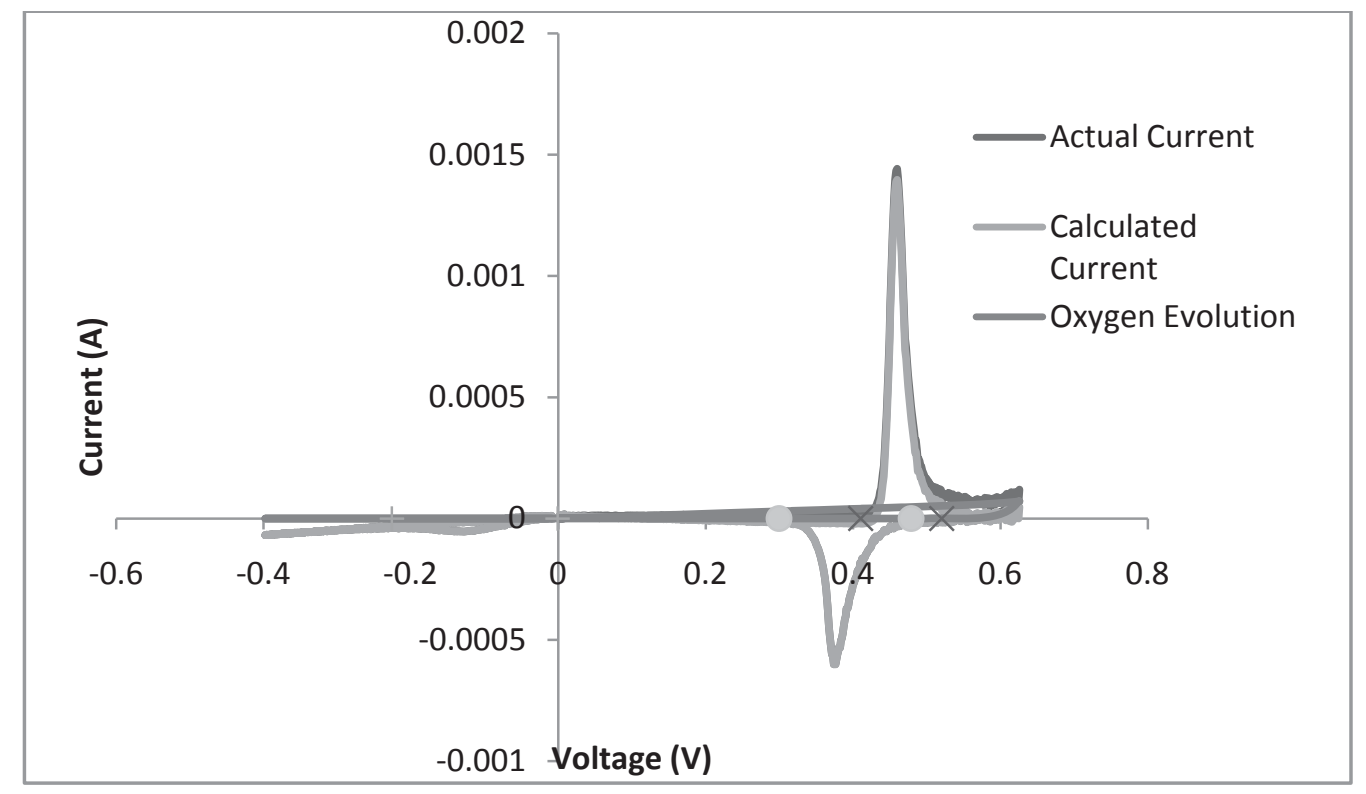

Figure B.1. CV plot of a nickel electrode with a secondary discharge plateau. 


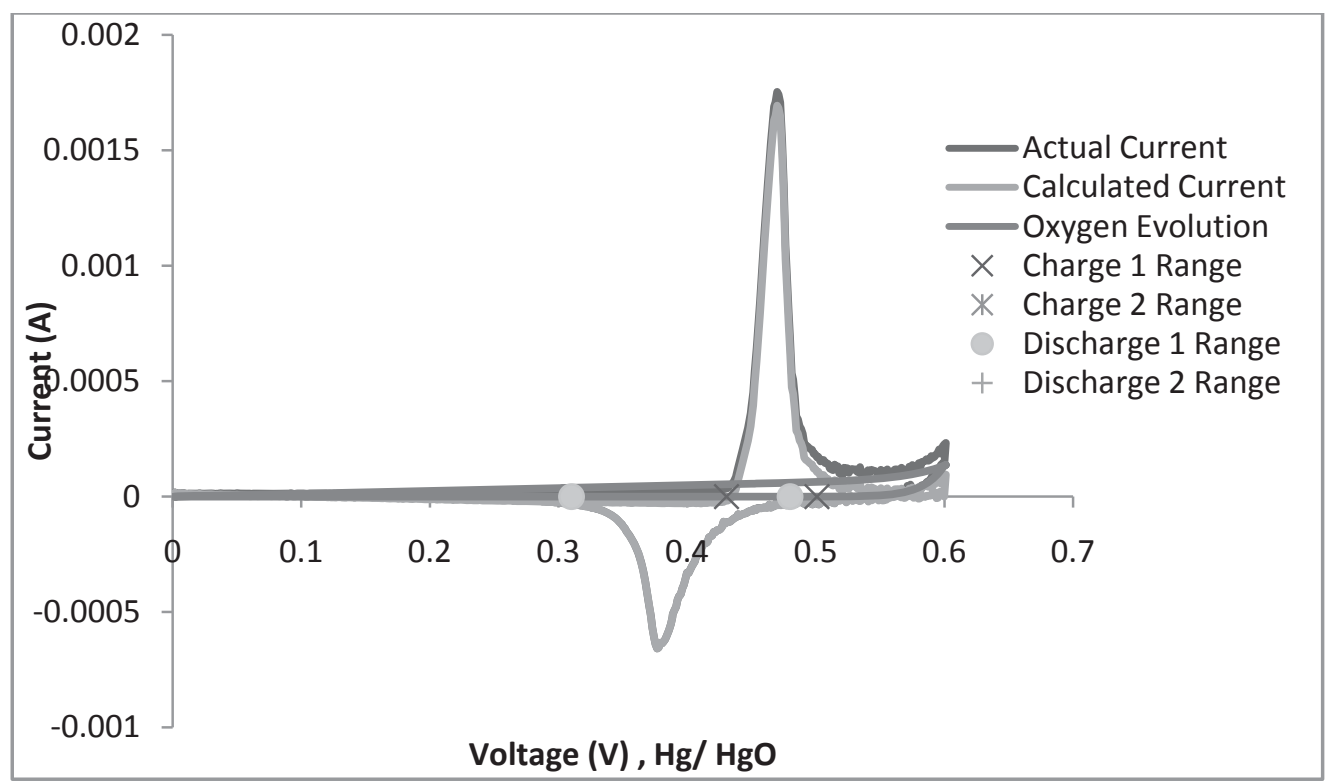

Figure B.2. CV plot of a nickel electrode cycled between 0 and $600 \mathrm{mV}$, which does not exhibit a secondary discharge plateau.

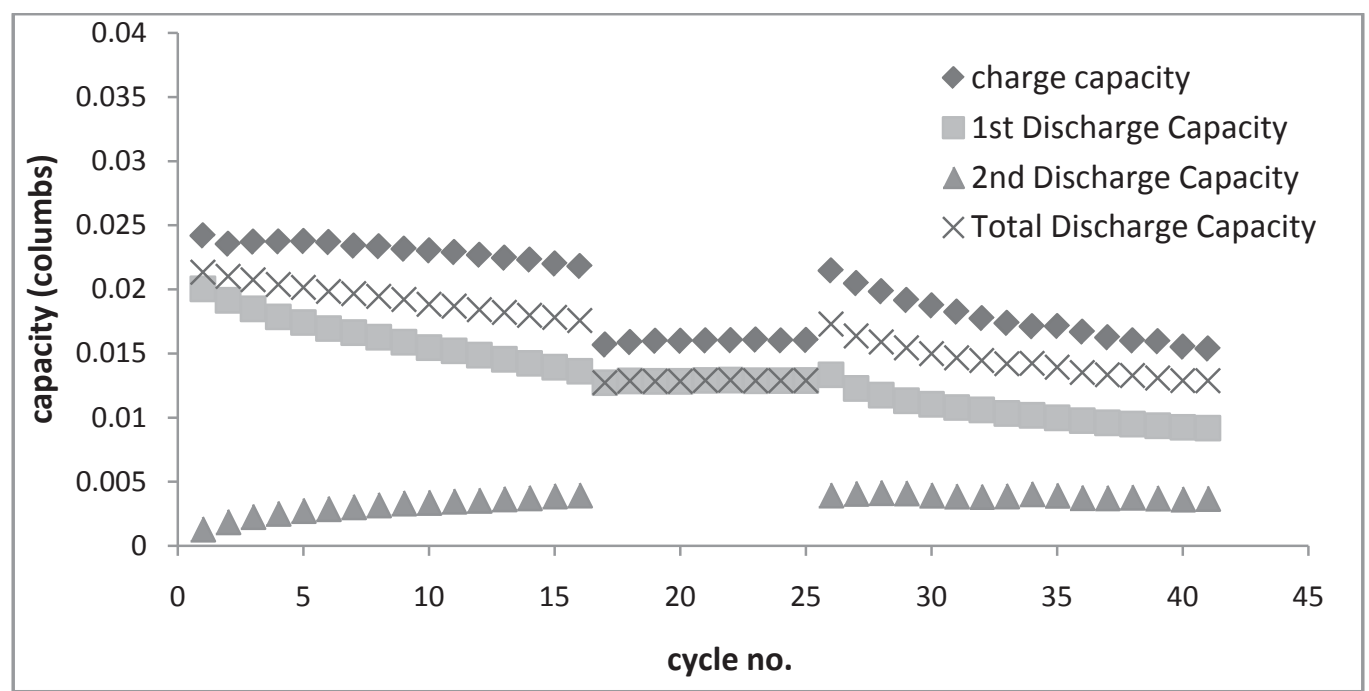

Figure B.3. Capacity variation of $\mathrm{Ni}(\mathrm{OH})_{2}$ deposited on a gold electrode. 


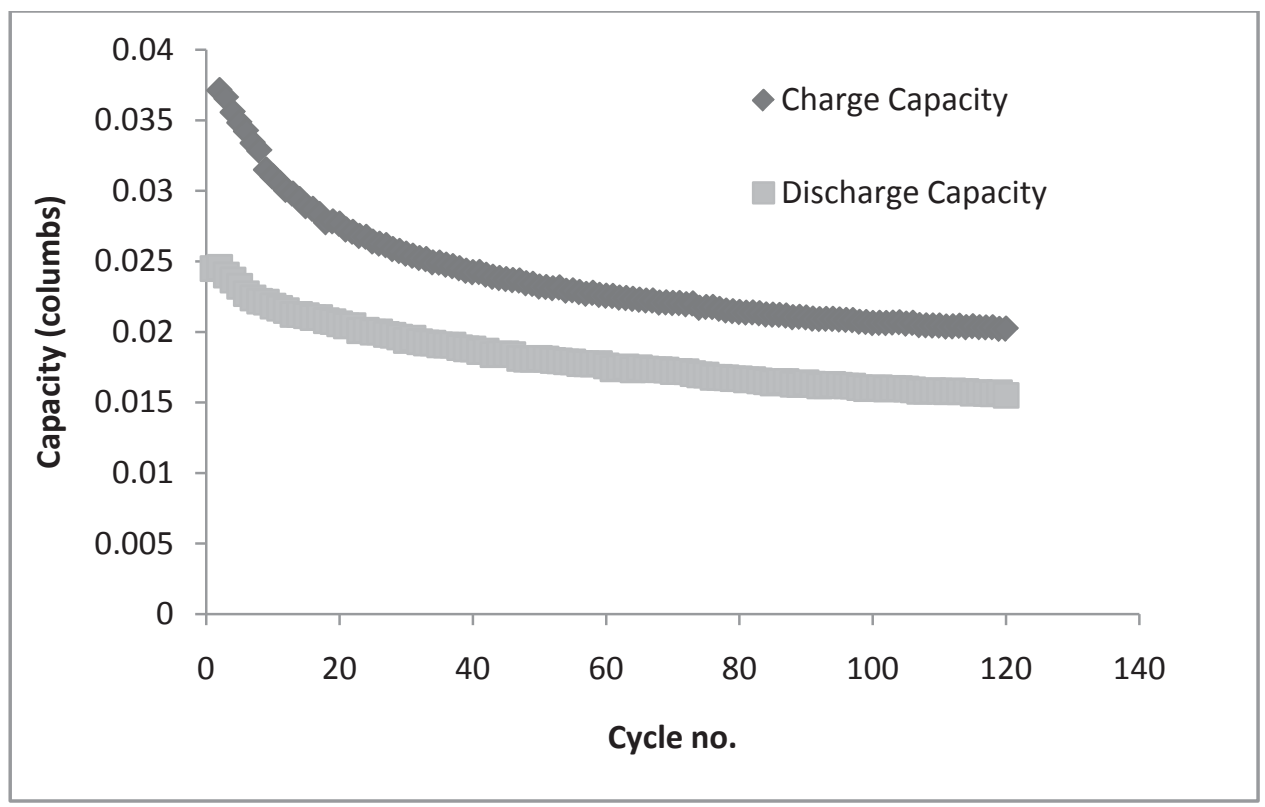

Figure B.4. Capacity variation with no secondary discharge $(0 \mathrm{mV}$ to $600 \mathrm{mV})$ in 3 wt. $\% \mathrm{KOH}$.

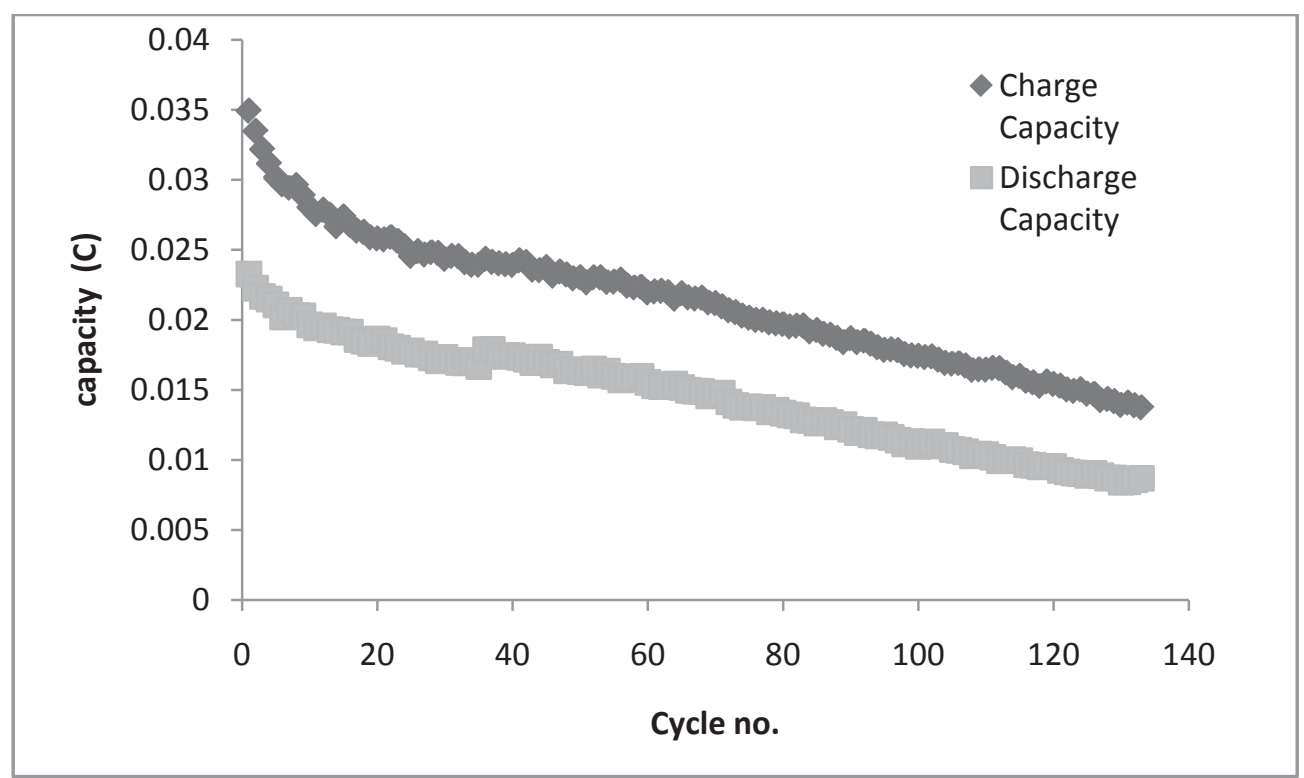

Figure B.5. Capacity variation with continuous $\mathrm{N}_{2}$ purging $(-400 \mathrm{mV}$ to $600 \mathrm{mV}$ ) for 133 cycles. No secondary discharge plateau is seen. 


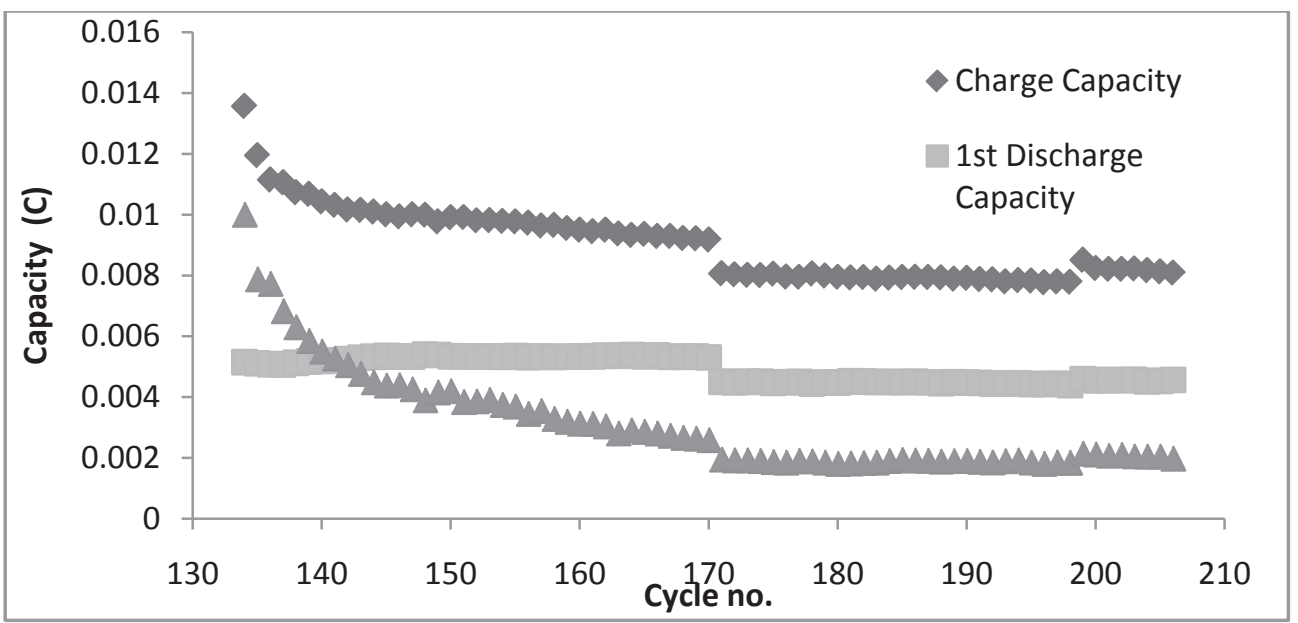

Figure B.6. Capacity variation during $\mathrm{O}_{2}$ purging (- $400 \mathrm{mV}$ to $600 \mathrm{mV}$ ) from the $134^{\text {th }}$ cycle to cycle 220 . A secondary discharge plateau appeared as soon as the $\mathrm{O}_{2}$ gas purge was begun with the $134^{\text {th }}$ cycle. 


\section{APPENDIX C}

\section{Evaluation of a Symmetric EC Capacitor with Commercial Carbon Sheet Electrodes}

\section{Electrode Preparation}

Circular commercial carbon sheet electrodes (carbon/PTFE sheet) were cut from the sheet using a $2 \mathrm{~cm}$ diameter punch giving an area of $2.81 \mathrm{~cm} 2(1.892 \mathrm{~cm}$ dia.). This commercial carbon sheet, the second one received, is $0.65 \mathrm{~mm}$ thick (dry). These electrodes were soaked for four days before assembly. The masses of these electrodes were $0.1219 \mathrm{~g}$ (1-layer) and $0.1215 \mathrm{~g}$ (1-layer), respectively. The BET surface area of the this sheet

( $0.0548 \mathrm{~g}$ sample) was found to be $1133 \mathrm{~m}^{2} / \mathrm{g}$. These electrode were assembled in a Swagelok PFA type cell, and electrochemical characterization was performed.

\section{Cyclic Voltammetry Studies}

Cyclic voltammetry studies have been performed at five different scan rates (beginning at $5 \mathrm{mV} / \mathrm{s}$, and starting a scan at $0 \mathrm{~V}$ ) in the potential range between $-1.4 \mathrm{~V}$ and $+1.4 \mathrm{~V}$ in $26 \mathrm{wt} \% \mathrm{KOH}$ (Fig. C.1). The higher scan rates, e.g., $100 \mathrm{mv} / \mathrm{s}$, are too fast and provide low capacities. The specific capacitance data for this symmetric cell (from Fig. C.1.) has been calculated and is listed in Table C.1. 


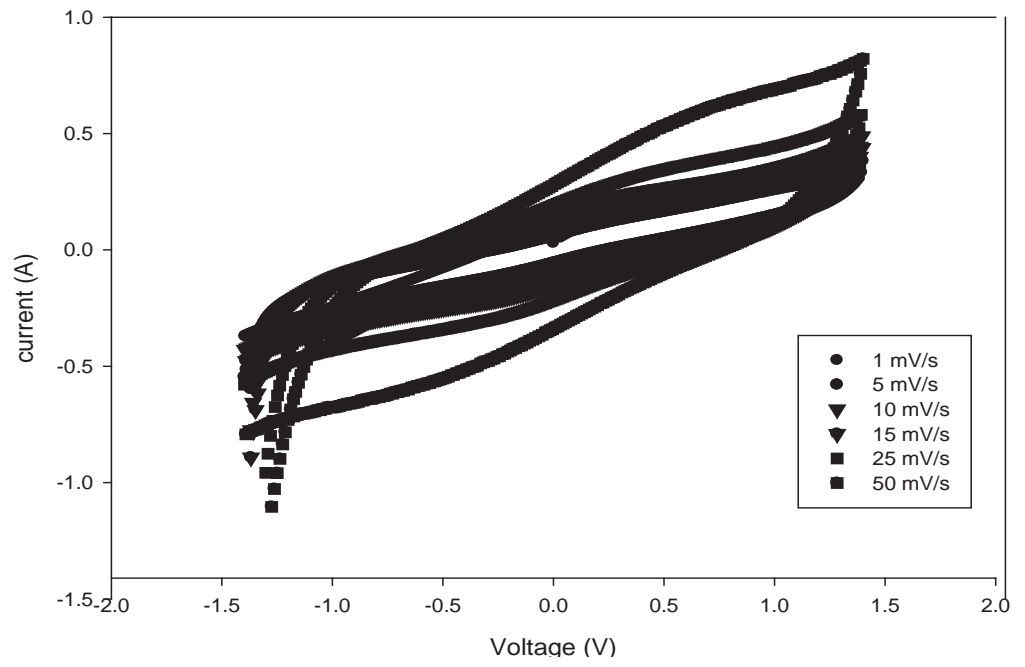

Figure C.1. Cyclic Voltammetry curves at 1, 5, 10, 25, and $50 \mathrm{mV} / \mathrm{s}$, scan rates, in $26 \mathrm{wt} \% \mathrm{KOH}$.

\section{Table C.1.}

Specific capacitance as a function of CV scan rate for the symmetric cell.

\begin{tabular}{|c|c|c|c|c|c|}
\hline $\begin{array}{l}\frac{\text { Scan }}{\text { Rate }} \\
(\mathrm{mV} / \mathrm{s}) \\
\end{array}$ & $\frac{\underline{\text { Cell }}}{\frac{\text { Discharge }}{\text { capacity }}}$ & $\frac{\frac{\text { Cell }}{\text { Capacitance }}}{(\mathrm{F})}$ & $\frac{\frac{\text { Single }}{\text { Electrode }}}{\underline{\text { Capacitance }}}$ & $\frac{\frac{\text { Specific }}{\text { Capacitance }}}{\frac{\text { of Single }}{\text { Electrode }}}$ & $\frac{\frac{\text { Specific }}{\text { Capacitance }}}{\frac{\text { of Single }}{\text { Electrode }}}$ \\
\hline 1 & 0.005124 & 13.18 & 26.35 & 216.2 & 19.08 \\
\hline 5 & 0.004744 & 12.20 & 24.40 & 200.2 & 17.67 \\
\hline 10 & 0.004695 & 12.07 & 24.15 & 198.1 & 17.48 \\
\hline 15 & 0.002033 & 5.229 & 10.46 & 85.79 & 7.572 \\
\hline 25 & 0.002323 & 5.975 & 11.95 & 98.02 & 8.652 \\
\hline 50 & 0.001275 & 3.278 & 6.555 & 53.78 & 4.746 \\
\hline
\end{tabular}




\section{Constant Current Charge/Discharge Cycle Test}

To define the charge and discharge behavior of the symmetric cell, five constant current cycles were scanned at 5 different current densities in the potential range of 0 to 0.9 V (see Fig. C.2.). The specific capacitance of the electrode has been calculated and reported in Table C.2. Specific capacitance decreases with increasing current density.

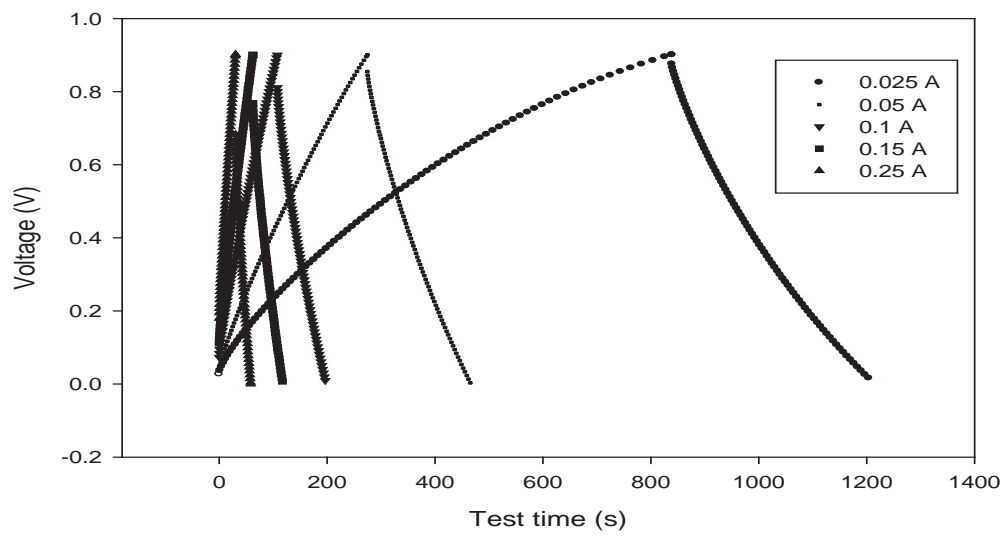

Figure C.2. Charge and discharge curves at different currents.

Table C.2.

Specific capacitance of the cell prepared from the commercial carbon sheet at different current densities (capacitance is calculated as discharge capacity $/ \Delta \mathrm{V}^{*} \mathrm{~m}$, and $\mathrm{SA}=1133 \mathrm{~m}^{2} / \mathrm{g}$ ).

\begin{tabular}{|c|c|c|c|c|c|}
\hline$\frac{\frac{\text { Charge }}{\text { /discharge }}}{\frac{\text { current }}{(\mathrm{A})}}$ & $\frac{\frac{\text { Cell }}{\text { Discharge }}}{\frac{\text { Capacity }}{\underline{\text { (Ah) }}}}$ & $\frac{\begin{array}{c}\text { Cell } \\
\text { Capacitance }\end{array}}{\underline{(\mathrm{F})}}$ & $\frac{\begin{array}{c}\text { Single } \\
\text { Electrode }\end{array}}{\text { Capacitance }}$ & $\frac{\begin{array}{c}\text { Specific } \\
\text { Capacitance }\end{array}}{\frac{\text { of Single }}{\text { Electrode }}}$ & $\frac{\begin{array}{c}\text { Specific } \\
\text { Capacitance }\end{array}}{\underline{\text { of Single }}}$ \\
\hline 0.025 & 0.002602 & 13.38 & 26.76 & 219.7 & 19.39 \\
\hline 0.05 & 0.002662 & 13.69 & 27.38 & 224.8 & 19.84 \\
\hline 0.1 & 0.002511 & 12.92 & 25.83 & 212.1 & 18.72 \\
\hline 0.15 & 0.002314 & 11.90 & 23.80 & 195.4 & 17.24 \\
\hline 0.25 & 0.001954 & 10.05 & 20.10 & 165.1 & 14.57 \\
\hline
\end{tabular}




\section{Cycle life}

For cycle life testing of the capacitor, the cell has been cycled at $0.08 \mathrm{~A} / \mathrm{cm}^{2}$. After the $1500^{\text {th }}$ cycle the specific capacitance started decreasing slowly, and by the end of cycle 4000, the capacitance dropped $8.8 \%$ relative to cycle 1 (see Figure C.3.).

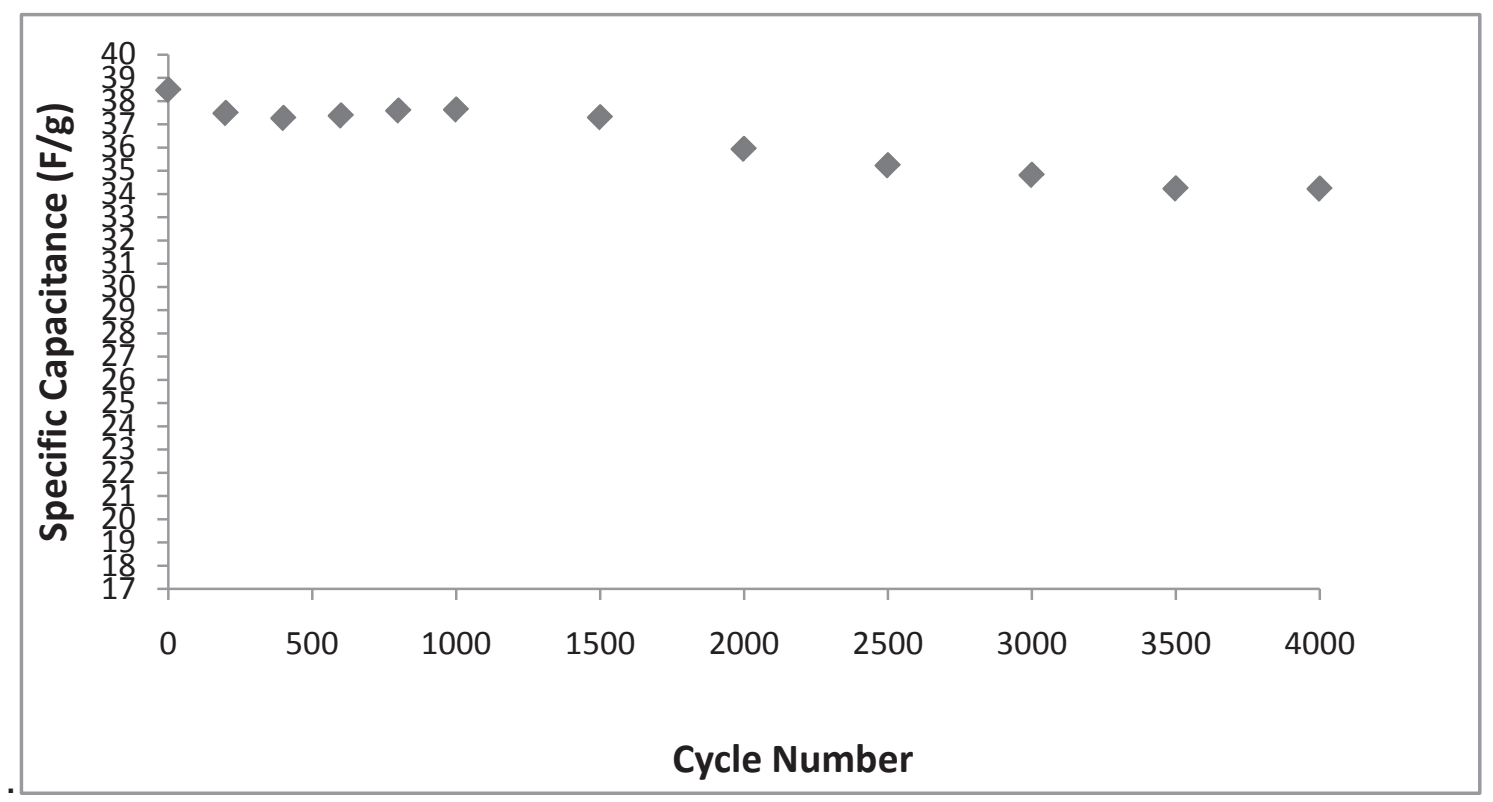

Figure C.3. Specific capacitance vs. cycle number.

\section{Impedance Studies}

Impedance studies were carried out using a model CH-660A Electrochemical Work Station. (frequency range $1 \mathrm{mHz}$ to $10 \mathrm{KHz}$ ); the $\mathrm{AC}$ signal amplitude was set at $0.005 \mathrm{~V}$. The experimental and calculated impedance data for the cell is plotted in a Nyquist plot in Fig. C.4. The equivalent circuit used for the impedance analysis is shown in Fig.3.8, and the best fit circuit parameters calculated for this circuit are listed in Table 3. The experimental error in the impedance data is $2.05 \%$ for this model and the chi-squared value is $4.20 \times 10^{-4}$. 


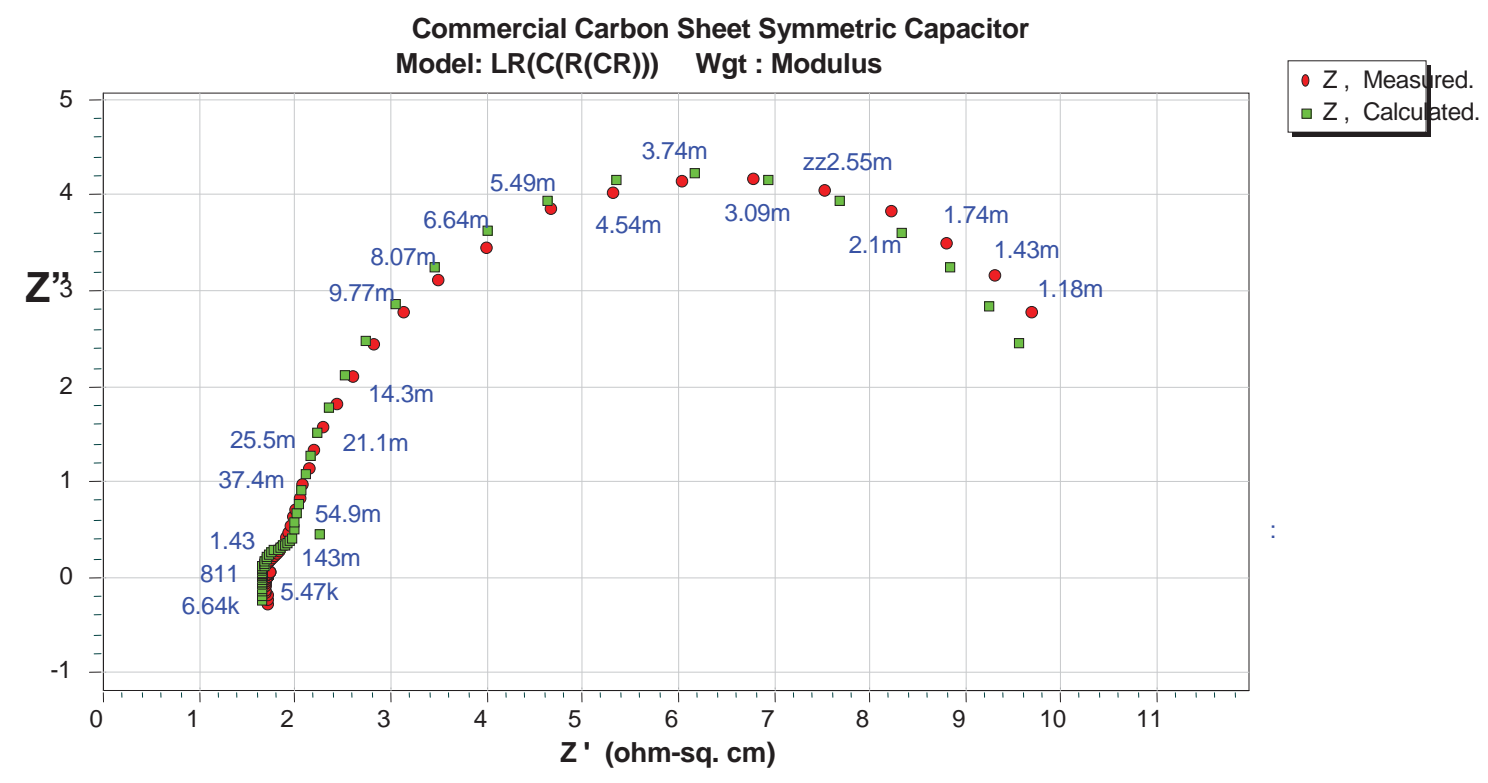

Figure C.5. Experimental (red circles) and calculated (green squares) impedance data, fitted with parameters in Table C.4.

Table C.4

Circuit parameters based upon fitting the impedance data in Fig. C.5 using Conway's circuit which includes pseudo-capacitance (refer Fig. 3.8).

\begin{tabular}{llc}
\hline \multicolumn{1}{c}{ Index } & Parameter & Value \\
\hline 1 Inductance & $\mathrm{L}\left(\mathrm{Henri} / \mathrm{cm}^{2}\right)$ & $6.92 \mathrm{E}-6$ \\
2 Solution resistance & $\mathrm{R}_{\mathrm{s}}\left(\mathrm{Ohm} / \mathrm{cm}^{2}\right)$ & 1.734 \\
3 Double layer & $\mathrm{C}_{\mathrm{dl}}\left(\mathrm{F} / \mathrm{cm}^{2}\right)$ & 1.071 \\
capacitance & $\mathrm{R}_{\mathrm{F}}\left(\mathrm{Ohm} / \mathrm{cm}^{2}\right)$ & 0.5135 \\
4 Faradic resistance & $\left(\mathrm{C}_{\phi}\right)\left(\mathrm{F} / \mathrm{cm}^{2}\right)$ & 4.125 \\
5 Pseudo-capacitance & $\mathrm{R}_{\mathrm{s}}\left(\mathrm{Ohm} / \mathrm{cm}^{2}\right)$ & 8.142 \\
6 Leakage resistance & & \\
\hline
\end{tabular}

